\title{
EL MANANTIAL DE LAS VÍCTIMAS. UNA LECTURA DESDE LA VICTIMOLOGÍA DE «EL MANANTIAL DE LA DONCELLA» (JUNGFRUKÄLLAN, I960) DE INGMAR BERGMAN.
}

\author{
Jorge GRACIA IBÁÑEZ \\ DOCTOR EN DERECHO \\ Professor CONVIDAdo. ESCOLA DE CRIMiNologia do PORTO (FDUP, OpORTO) \\ INVESTIGADOR DEL LABORATORIO DE SOCIOLOGÍA JURÍDICA (UNIVERSIDAD DE ZARAGOZA)
}

SUMARIO: I. Introducción: con los estudiantes de Victimología en el bosque de Bergman. II. «El manantial de la doncella» en el cine de Ingmar Bergman: el rostro humano y la fuente del dolor. III. La Victimología y el redescubrimiento de la víctima. IV. Una posible guía de lectura desde la Victimología. IV.I. La compasión y la doncella. IV.2. El deseo de venganza y el caballero. IV.3. El sentimiento de pérdida, el duelo y los familiares. V. Conclusiones: el manantial de las víctimas.

RESUMEN: En este texto proponemos una guía de lectura, a partir de la Victimología, de la película «El manantial de la doncella» (Jungfrukällan, I960) dirigida por Ingmar Bergman. Se analizan, en primer lugar, las características de la obra que la convierten en un material docente óptimo para la enseñanza universitaria de la Victimología. En segundo lugar se realiza una síntesis crítica de la emergencia de la victimología como disciplina científica y del proceso de redescubrimiento de las víctimas en el Derecho penal y la justicia criminal analizando algunas de sus paradojas y contradicciones. En tercer y último lugar se aborda el análisis concreto de algunos temas presentes o sugeridos por la película en una lectura en clave victimológica conectándolos con tres emociones: la compasión, el deseo de venganza y el sentimiento de pérdida.

PAlAbras ClAVE: cine y derecho, Victimología, emociones, derecho penal, compasión, venganza, sentimiento de pérdida, derechos de las víctimas.

ABSTRACT: The main aim of this paper is to provide a reading guide from a victimological point of view for the film «The Virgin Spring» (Jungfrukällan, I960) directed by Ingmar Bergman. We analyze first the characteristics of the work that make of it an excellent tool for the victimology lectures. Secondly, a critical overview of the emergence of Victimology as a scientific discipline and the process of rediscovery of victim in criminal law and criminal justice by examining some of its paradoxes and contradictions is performed. Finally we face a concrete analysis of some issues present or suggested by the film connecting them with three key human emotions: compassion, desire for revenge and sense of loss.

KEYwORDs: law and film, Victimology, emotions, criminal law, compassion, revenge, sense of loss, rights of the victims. 


\section{Introducción: con los estudiantes de Victimología en el bosque de Bergman}

El cine resulta un poderoso medio de transmisión de conocimiento. Por eso mismo parece una herramienta pedagógica especialmente adecuada en las clases universitarias, amigable para los estudiantes y de la que podemos obtener un amplio beneficio académico. Partiendo, como propone Juan Antonio Gómez, de la consideración de las películas como textos, podemos comprender lo cinematográfico «dentro de una tradición histórico-cultural en constante actualización, la cual actúa conformando, a su vez, esta misma tradición en sus interpretaciones concretas, posibilitándose su entendimiento en razón de su discurso propio (estético, político, sociológico, económico, etc.), sin que quepa otorgar mayor peso a ninguno de los discursos sobre los demás» ${ }^{\mp}$. Por todo ello, y especialmente por ese potencial proteico e interdisciplinar del texto filmico, no es de extrañar que en los últimos tiempos el cine haya entrado con fuerza en las aulas de las Facultades como auxiliar de la tarea docente.

Como es obvio, no toda película posee el mismo valor pedagógico aunque trate un tema incluido en un determinado programa de estudios. Además de la calidad y profundidad de la obra seleccionada, la forma en la que se estructure la sesión, se introduzca el material y se motive a los alumnos será clave para evitar una subutilización del potencial del cine en las aulas.

En el caso concreto de la enseñanza del Derecho (y de otros estudios relacionados como la Criminología) existe el peligro de utilizar las películas como meros elementos ilustrativos de un caso o de una materia jurídica determinada. De esta manera, aunque en la superficie adoptamos un enfoque interdisciplinario, en lo profundo, ese cruce de conocimientos no cuestiona ni aporta elementos nuevos sino que suele quedar en el papel de mero ejemplo o ilustración ${ }^{2}$. Deberíamos, por lo tanto, evitar un uso del cine en las aulas que sea más intuitivo que realmente reflexivo.

Este artículo parte de una experiencia y una propuesta muy concreta: el visionado como actividad complementaria en la asignatura de Victimología, inserta en el contenido curricular de la licenciatura de Criminología, de una película a priori poco convencional como es «El manantial de la doncella» (Jungfrukällan, I960) dirigida por Ingmar Bergman. Pero, ¿dónde residiría el carácter anticonvencional del filme propuesto?

Tiene que ver, en primer lugar, con su director: Ingmar Bergman, figura clave de la historia del cine y epítome del denominado cine de autor. El director imprimió en todos y cada uno de sus fotogramas sus obsesiones personales reflejando un mundo aceradamente personal y a la vez, como suele acontecer solo en la obra de los más grandes, plenamente universal. En cualquier caso, no es un director fácil ni complaciente. Casi todas sus películas requieren un espectador activo y un esfuerzo de atención que puede ser mayor para estudiantes jóvenes habituados a otro tipo de productos audiovisuales muy alejados del rigor conceptual y estético que el autor sueco imprimía a sus obras ${ }^{3}$.

\footnotetext{
GómEz GARCíA, J.A., «Derecho y cine: El rito, o el derecho y el juez según el realismo jurídico escandinavo», Revista de Derecho UNED, n. 3, 2008, pág. I05.

2 Thury Cornejo, V., «¿El cine nos aporta algo para la enseñanza del Derecho?», Academia. Revista sobre enseñanza del Derecho, año 7, nº. I4, 2009, pág.6o.

${ }^{3}$ Como acertadamente resume Juan Antonio Gómez, «El estilo narrativo de Bergman es intencionadamente lento, articulado sobre escenas y un montaje milimétricamente estudiados con el fin de que los actores puedan
} 
En segundo lugar, y en relación con esta película en concreto, nos enfrentamos a una obra peculiar: extrañamente naturalista, que se sirve de algunos símbolos y presenta, en suma, un fuerte trasfondo filosófico. A ello hay que añadir que no se trata de una obra ambientada en la época actual sino en la edad media escandinava. A simple vista sería un material de partida en el que la conexión con la Criminología y la Victimología como saberes esencialmente contemporáneos puede no parecer tan evidente como en otras películas más convencionales ${ }^{4}$.

Todo ello implica la necesidad de decodificar algunos de esos símbolos, de explicar algunos conceptos y, sobre todo, de aprender a mirar una ficción que está contada de una forma a la que no estamos demasiado acostumbrados. Igualmente nos exige que no vayamos en contra de esa complejidad sino que, más bien, la sepamos integrar para que la película hable por sí misma sin forzar nada y no se convierta en una mera ilustración ficcional de algunos contenidos del programa de estudios. Por eso mismo, las posibles lecturas tendrán que ir siempre un poco más allá de la evidente conexión de la trama con el objeto de la asignatura. Entonces, ¿cuáles serían los beneficios de la elección de una película como esta?

En primer lugar, al tratarse de una auténtica obra maestra, es capaz de soportar múltiples lecturas. Está en la naturaleza de los clásicos: acaban por dialogar con los espectadores de cualquier época porque resultan, de alguna forma, siempre contemporáneos. No estaríamos tanto ante una película histórica medieval sino ante una película ambientada en la edad media pero que hablaba también de la Suecia de su época de rodaje y sobre la que nosotros podemos proyectar igualmente muchos elementos de nuestra realidad social.

En segundo lugar, aunque relacionado con el anterior, tiene la ventaja de la abstracción que el depuradísimo estilo de Bergman alcanza yendo siempre a lo más esencial y profundo de las cuestiones que aborda. Elementos que sugiere o presenta la película, aislados de la época actual y bajo la estilizada mirada del director, se vuelven puros y casi abstractos y, por tanto, más individualizables para la discusión. De esta forma, esta obra bergmaniana inspira y apoya una reflexión profunda sobre una serie de conceptos clave para la Victimología: violencia, dolor, compasión, deseo de venganza, memoria, inocencia, justicia, trauma y sentimiento de pérdida, entre otros.

Finalmente, en tercer lugar, se trata de una película tremendamente emocional. Una obra que, en su crudeza, conmueve y remueve al espectador. Aunque parezca difícil reconciliar depuración de estilo y abstracción con emoción, el director es capaz de hacernos empatizar con el sufrimiento de sus personajes, que no son simples trasmisores de ideas sino entes tridimensionales psicológicamente complejos. En este sentido, como bien ejemplifica este filme de Bergman, la capacidad del mejor cine de atraer emocionalmente a

explayarse en la transmisión de los estados anímicos de sus personajes, y sobre imágenes de una excepcional limpidez, casi única en el arte cinematográfico». Gómez GARCíA, J.A., «Derecho y cine: El rito, o el derecho y el juez según el realismo jurídico escandinavo», cit., pág. I07.

${ }^{4}$ Estoy de acuerdo con Thury en el sentido de que no siempre para explicar Derecho $u$ otras materias afines debemos recurrir a películas jurídicas entendiendo como tales aquellas que de una forma explícita remiten al funcionamiento del sistema judicial. Aquellas en las que, para entendernos, salen jueces, fiscales y abogados o hay algún juicio en la trama. Es más creo que lo interesante es utilizar el cine para insertar lecturas jurídicas de temas no jurídicos como una forma de acercar el Derecho a la sociedad. Thury Cornejo, V., « ¿El cine nos aporta algo para la enseñanza del Derecho?», cit., pág.77. 
los espectadores supone un arma pedagógica poderosa para lograr la motivación que los conceptos expuestos académicamente por si mismos pocas veces pueden lograr 5 . Permite aislar conceptos complejos y reflexionar sobre ellos encarnados en una historia al tiempo trágica y conmovedora. Lo que, trasladando al cine un cierto concepto aristotélico de tragedia, nos permitiría enfrentarnos de un modo agradable y personalmente no doloroso a circunstancias que podrían ocurrir en la vida humana ayudándonos a aprender sobre la naturaleza de esta ${ }^{6}$.

Partiendo de estas premisas, ¿porque no adentrarse con los estudiantes de Victimología en el trágico bosque medieval que Bergman recreó en esta película? En este artículo intentaremos proponer una especie de guía de visionado o lectura en una determinada clave victimológica que nos ayude a reflexionar sobre determinados conceptos nucleares en el estudio de la disciplina que están sugeridos por la gran potencia evocadora de la obra escogida. No se trata tanto de agotar los temas sino de esbozar una guía para facilitar su abordaje en las aulas.

Para ello, comenzaremos por algunas notas sobre la figura de Bergman, especialmente acerca de la posición de esta película en el conjunto de su extensa y compleja producción. Después pasaremos a analizar, en sus elementos esenciales, el resurgimiento del interés por la víctima y el origen y desarrollo de la Victimología como ciencia. Finalmente desarrollaremos con algo más de detalle, y siempre desde ese enfoque victimológico, algunos de los temas que el filme elegido plantea o sugiere.

\section{II. «El manantial de la doncella» en el cine de Ingmar Bergman: el rostro humano y la fuente del dolor.}

Resulta una tarea realmente compleja tratar de sintetizar en unas cuantas páginas el alcance de la obra de Ingmar Bergman. Sobre todo porque hubo muchos Bergman diferentes a lo largo de una carrera tan extensa y fructífera.

Para empezar, habría que distinguir entre el Bergman dedicado al teatro y el Bergman cineasta. Por razones que tienen que ver con la distinta naturaleza de estas artes, sobre todo con lo efímero de los montajes teatrales, conocemos mucho mejor al Bergman cineasta que al Bergman que revolucionó el teatro con sus puestas en escena desde el Teatro Real Sueco, el famoso Dramaten de Estocolmo. Con todo, su mundo cinematográfico no puede entenderse plenamente, aislado de su dedicación al teatro.

Resuenan en su obra numerosas influencias dramáticas, siendo la más importante la ejercida por Strindberg, uno de los padres indiscutibles del teatro europeo

\footnotetext{
${ }^{5}$ Thury CoRnejo, V., «¿El cine nos aporta algo para la enseñanza del Derecho?», cit., pág.76.

${ }^{6}$ Nussbaum, M.C. Emociones políticas, $\mathrm{I}^{\mathrm{a}}$ edición, Barcelona, Paidos, 20I4, pág. 2I7.

${ }^{7}$ He tenido la ocasión de utilizar este material en mis clases de Victimología. A los alumnos la película les sorprende y, en general, les mueve a reflexionar. Se puede proyectar la sesión con la película, como yo hice en mis clases, cuando el curso está algo avanzado y los alumnos han empezado a asimilar algunos conceptos. Así la discusión es siempre más rica. Se puede optar por verla en el aula o por que la vean en su casa dejando el tiempo completo de clase para la discusión. Una ventaja adicional es su relativamente corta duración (no llega a la hora y media) que permite un debate relajado en una sesión incluso aunque se pase previamente la película. Otra opción es la de visionar algunos fragmentos escogidos.
} 
contemporáneo ${ }^{8}$. La inclemencia de la mirada, la fiereza de su visión sobre las relaciones humanas y algo de la vehemencia casi demente del teatro de Strindberg nutre buena parte de la obra cinematográfica de Bergman que es también un estupendo guionista. Está influencia es más clara en aquellas películas que se centran en las relaciones familiares y de pareja, desde «Un verano con Mónica» (Sommaren med Monika, I953), «Fresas Salvajes» (Smultronstället, I957) o «Como en un espejo» (Såsom $i$ en spegel, I96I) hasta «Fanny y Alexander» (Fanny och Alexander, I982) pasando por «Sonata de Otoño» (Höstsonaten, I978), «Gritos y susurros» (Viskningar och rop, I972), «Secretos de un Matrimonio» (Scener ur ett äktenskap, I973) o «Saraband» (Saraband, 2003).

Pero si el teatro (o al menos cierta forma de teatro) podría definirse, tomando prestado el título del célebre monólogo de Jean Cocteau, como la voz humana ${ }^{9}$, una buena forma de definir el cine, tal como lo entendía y practicaba Bergman, sería considerarlo como la representación del rostro humano. En sus películas abundan los primeros (incluso primerísimos) planos que son un recurso estético de gran belleza pero que indudablemente significan algo más: implican una voluntad de penetración, de profundidad, de indagación del alma ${ }^{\text {Io }}$.

En esta compleja y apasionante obra se inserta «El manantial de la doncella» (Jungfrukällan, I960) que podríamos situar en la fase de consolidación de la carrera y del prestigio internacional de su director ${ }^{\mathrm{II}}$. La cinta forma parte, junto con «El séptimo sello» (Det sjunde inseglet, I957), de un díptico de ambientación medieval que generó en su momento, en un sector de la crítica, cierta confusión al etiquetar a Bergman, algo reductoramente, como una especie de cineasta religioso y místico obsesionado por el silencio de $\operatorname{Dios}^{\mathrm{I2}}$.

La película es quizás la menos valorada de este díptico medieval bergmaniano. Frente a la densidad metafísica y conceptual de «El séptimo sello» (Det sjunde inseglet, 1957) se antoja, al menos en apariencia, como una obra más seca y simple, siendo tradicionalmente considerada por la crítica como menos compleja y conseguida. Aunque ambos filmes se sirven de símbolos, los manejan de forma muy diferente: «El séptimo sello» (Det sjunde inseglet, I957) es profundamente alegórica y «El manantial de la doncella» (Jungfrukällan, I960) es perturbadoramente naturalista ${ }^{13}$. No obstante, a pesar de esas

\footnotetext{
${ }^{8}$ Para un excelente recorrido acerca de la influencia de Strindberg en Bergman vid. TöRNQVIST, E. Strindberg in Bergman, 20I3 (disponible en http://ingmarbergman.se/en/universe/strindberg-bergman; fecha de consulta: 29.08.2014).

${ }^{9}$ Cocteau, J., La voz humana. La gran separación, Barcelona, Nuevo Arte Thor, I986.

${ }^{10}$ Como recuerda un destacado comentarista de la obra de Bergman, «Su meta es la realización de un retrato esencial, una imagen del ser humano con su corazón expuesto y palpitante, la imagen de lo que cada uno de nosotros parecemos despojados de autoengaños, evasivas y mentiras. Tal reducción a lo esencial nos proporciona un espejo en el que podemos vernos como realmente somos, cara a cara». KALIN, J., The Films of Ingmar Bergman, Cambridge, Cambridge University Press, 2003, pág.II.

${ }^{\text {II }}$ De hecho la película ganó el Oscar a la Mejor película extranjera en representación de Suecia, y el Gran Premio del Jurado en el Festival de Cannes.

${ }^{12}$ En palabras del propio Bergman la motivación religiosa de esta película es muy dudosa. «La idea de Dios hacía ya mucho que había empezado a resquebrajarse y quedaba más que nada como adorno. Lo que en realidad me interesó fue la atroz historia de la chica, los violadores y la venganza. Mis propias ideas religiosas habían hecho mutis por el foro». Bergman, I., Imágenes, Barcelona, Tusquets, I992, pág. 2I5.

${ }^{13}$ No obstante, aun siendo ambas películas magistrales, comparto la opinión de Triggs al afirmar que quizás «El manantial de la doncella», en su simplicidad, resulte finalmente una obra «más sutil, más trágica, y, en el mejor de los sentidos, más perturbadora». TRIGGS, J.A., Allegory and Naturalism in Ingmar Bergman's Medieval
} 
diferencias, muchos analistas sitúan ambas obras de inspiración medieval insertas dentro de un mismo periodo de películas de contenido simbólico dentro de la carrera de Bergman $^{\text {I4 }}$.

La anécdota argumental de «El manantial de la doncella» (Jungfrukällan, I960) proviene de una balada sueca fijada a finales del S.XIV conocida como «La hija de Torë de Vänge» que solía ser cantada por los frailes mendicantes que recorrían los caminos pidiendo limosna para la construcción de nuevos templos ${ }^{15}$.

El viernes de pasión, Karin, hija de Töre e Mareta, debe llevar unos cirios a la iglesia situada más allá de un bosque oscuro. La doncella le pide a su padre que la acompañe Ingeri, su hija adoptiva. Ingeri está enfadada con Karin porque la noche anterior había bailado con Simón, el hombre que la ha dejado embarazada. Por esta causa dirige una maldición pagana contra Karin. Emprenden el camino las dos muchachas pero antes de penetrar en el bosque, temiendo los efectos de la maldición Ingeri le pide a Karin que vuelvan. Pero la doncella orgullosa decide seguir el camino sola, dejándola atrás. En un claro del bosque se encuentra con tres pastores: uno de ellos delgado por el hambre, otro mudo y un niño. Conversan distendidamente con ella, tocan música y deciden compartir las provisiones. Al abrir el zurrón, un sapo, que había colocado Ingeri como parte del ritual de mal de ojo, salta de una hogaza de pan abierta. La escena se enrarece súbitamente. Los pastores abandonan las buenas maneras y violan a la doncella ante la mirada horrorizada del niño. Tras violarla, le dan muerte a garrotazos y roban sus ricas vestimentas.

Al hacerse de noche, los tres pastores piden alojamiento, sin saberlo, en casa de Torë que, como buen cristiano, les ofrece refugio y comida. Al bendecir los alimentos, como hizo Karin en el bosque antes del brutal ataque, el niño vomita. Al ir a acostarse, los pastores ofrecen a Mareta, la madre, las ropas robadas diciendo que pertenecían a una hermana suya fallecida pero ella reconoce el rico vestido que su hija había estrenado la misma mañana que salió de casa. Manteniendo la frialdad, se lo comunica a su esposo. El padre decide vengar la muerte de la hija matando sin piedad a los tres pastores. Al rematar la cruenta matanza, toda la familia va en busca del cadáver de Karin. Cuando delicadamente lo levantan, del lugar donde reposaba el cuerpo asesinado de la doncella surge un manantial de aguas cristalinas. Interpretando esto como una señal divina, Torë promete construir allí la primera iglesia de piedra de la región en memoria de su hija y a mayor gloria de Dios y de sus inescrutables designios ${ }^{\mathrm{I} 6}$.

Films, I988, pág.8. (disponible en http://triggs.djvu.org/global-language.com/triggs/Bergman/Bergman.html; fecha de consulta: 24.06.20I4).

${ }^{14}$ Para García Gil, la obra de Bergman puede dividirse en cinco períodos: obras de juventud (I945-I948), de contenido psicológico (I948-I955), de contenido simbólico (I956-I963), de expresión crítica (I964-I980), y de reconstrucción genealógica (I98I-2005). La película que nos ocupa formaría parte de ese período simbólico junto con «El séptimo sello» (Det sjunde inseglet, I957), «Fresas salvajes» (Smultronstället, I957), «En el umbral de la vida» (Nära livet, I958), «El rostro» (Ansiktet,I958), «El ojo del diablo» (Djävulens öga, I960), «Como en un espejo» (Såsom i en spegel, I96I), «Los comulgantes» (Nattvardsgästerna, I963) y «El silencio» (Tystnaden, I963). El mencionado autor, aunque quizás algo simplificadoramente, caracteriza este periodo «como genuinamente existencial, con una búsqueda intelectual y religiosa deudora de la influencia que tuvo en el sueco la filosofía del danés Sören Kierkegaard». GARCíA-GIL, J. M., «Ingmar Bergman: el existencialismo en el cine o un verano con Ingmar», Isagogé, $\mathrm{n}^{\circ} .4,2007$, pág. 62.

${ }^{15}$ Romasanta Iglesias, O., Calvo Varela, C. «Jungfrukällan: um conto maravilhoso», Agália, $n^{\circ}$ 97-98 I semestre, págs. 63-64.

${ }^{16}$ Esta sinopsis está tomada esencialmente del mismo artículo. RomasAnTA IGlesias, O., CALVo VARELA, C. «Jungfrukällan: um conto maravilhoso», cit., págs. 64-65. 
Sobre esta sencilla base, Bergman concibió un filme tan argumentalmente simple como su fuente de inspiración literaria. Pero lo hizo enriqueciendo e intensificando cada detalle hasta que el conjunto parece casi insoportablemente lleno de potencia y terror, conmoviendo hasta las entrañas ${ }^{17}$. Como señaló un crítico de la época, aunque el significado del filme parece explícito en la superficie, es universal en su profundidad ${ }^{18}$.

La película sugiere muchos más elementos que trascienden la simple concatenación de hechos narrados. Su resonancia casi mítica, la poderosa recreación del bosque como un espacio metafísico y aterrador donde habitan el mal y la muerte, el contexto sociocultural en el que se mezclan y se confunden el cristianismo y la pervivencia de los cultos nórdicos paganos y la cruda representación de la violencia y sus devastadores efectos, la convierten en una película hipnótica, realmente única.

Como analizaremos después con más detalle, la obra gira en torno a la impactante escena de la violación y muerte de la doncella. Es difícil no pensar al verla en episodios más o menos actuales de la crónica negra muy similares que están en el recuerdo de todos ${ }^{\text {19 }}$. El caso que presenta la película, a pesar de suceder en una época lejana, parece contener, con una precisión y una pureza de formas admirables, todos los miedos atávicos relacionados con la victimización y que tan presentes continúan estando en nuestras sociedades contemporáneas.

La lectura de este texto filmico bergmaniano desde la Victimología resulta, por lo tanto, legítima e incluso diría que especialmente pertinente. Pero, antes de entrar de lleno en ella, para mejor centrar el tema, conviene que hagamos algunas consideraciones básicas sobre la Victimología como ciencia y el redescubrimiento de la víctima.

\section{La Victimología y el redescubrimiento de la víctima}

Desde el punto de vista criminológico, las víctimas jugaban un papel secundario hasta hace relativamente poco tiempo. No obstante la situación ha cambiado considerablemente y las víctimas han ido ocupando una posición cada vez más central. Ello se ha puesto de manifiesto en el amplio reconocimiento de sus derechos y la articulación de programas de atención especializados, un papel más relevante en el diseño de las políticas criminales y, en general, una mayor visibilización social y política. Garland ha descrito este fenómeno como el del retorno de la víctima, de modo que ésta ha irrumpido en el centro del escenario del teatro del delito y, ahora, «el nuevo imperativo político es que las víctimas deben ser protegidas, se deben escuchar sus voces, honrar su memoria, deben poder expresar su ira y debe haber respuestas a sus temores» ${ }^{20}$. Este proceso de retorno o mejor de redescubrimiento de la víctima (estaba allí, pero no se la veía) no está exento de contradicciones y paradojas. Desde luego está conectado con el gran auge de la

\footnotetext{
${ }^{17}$ Vernon Young, V, «Jungfrukällan (The Well of the Virgin) by Ingmar Bergman», Film Quarterly, vol. I3, n. 4 ,I960, pág. 43.

${ }^{18}$ VeRnON YounG, V, «Jungfrukällan (The Well of the Virgin) by Ingmar Bergman», cit., pág.45.

19 Solo en el contexto español podríamos hablar, sin remontarnos excesivamente en el tiempo, de los muy mediáticos casos de Marta del Castillo, las niñas de Alcasser, Anabel Segura o de Mariluz Cortés, entre otros

${ }^{20}$ GARlAnd, D., La cultura del control. Crimen y orden social en la sociedad contemporánea, Barcelona, Gedisa, 2005, pág. 46.
} 
Víctimología, desde sus orígenes académicos, allá por los años cuarenta del pasado siglo, hasta sus más recientes desarrollos.

El inicio de la Victimología como disciplina científica surge de los trabajos de Mendelsohn y von Hentig ${ }^{2 \mathrm{~T}}$. Ambos autores parten de estudios empíricos para analizar las relaciones entre víctima y victimario así como el papel de las víctimas en su propia victimización criminal $^{22}$. Para algunos autores la Victimología sería una disciplina autónoma mientras que otros la consideraron desde el inicio como una rama de la Criminología dedicada al análisis de la víctima y de los procesos de victimización ${ }^{23}$. La discusión sobre la autonomía o no de la disciplina respecto de la Criminología, aunque tenía sentido desde el punto de vista del proceso de institucionalización y desarrollo de la Victimología, parece menos relevante en este momento si se tienen en cuenta las evidentes conexiones entre las dos disciplinas y el hecho de que comparten método y, en muchos aspectos, objeto de estudio. No sería posible estudiar en profundidad el hecho criminal sin incluir a las víctimas además de a los victimarios. De acuerdo con Morillas Fernández, «la Criminología presenta un denotado carácter integrador por cuanto es la expresión científica de un todo donde se integran distintas disciplinas entre las que destacaría sobremanera la Victimología ${ }^{24}$.

En un primer momento, los autores se centran en la clasificación de estas víctimas basándose, en buena medida, en el grado de responsabilidad de estas en su propia victimización o en su grado de vulnerabilidad. Desde ese punto de vista, y a pesar de las importantes diferencias entre ellos, los primeros trabajos de los padres de la Victimología impulsaron un conjunto de teorías que con posterioridad fueron criticadas como culpabilizadoras de la víctima (blaming the victim). Estas concepciones teóricas se centraban en los mecanismos de precipitación del resultado por parte de las propias víctimas (victim precipitation $)^{25}$.

El proceso de institucionalización como disciplina académica tuvo un importante punto de inflexión en la celebración del I Simposium Internacional sobre Victimología en Jerusalem en $1973^{26}$. La Sociedad Mundial de Victimología, fundada en I979, entiende la

\footnotetext{
${ }^{21}$ Aunque el término Victimología fuera utilizado por vez primera por Werthan en su obra The show of violence. WERTHAN, F., The show of violence, New York, Doubleday, I949.

${ }^{22}$ Hentig, H. von, The Criminal and His Victim: Studies in the Sociology of Crime, New Haven, Yale University Press, I948; Mendelsohn B., «Une nouvelle branche de la science bio-psycho-sociale : la victimologie», Revue Droit Pénal et de Criminologie, i958, págs. 619-628.

${ }^{23}$ Como señala Sandra Walklate esa discusión en torno a la autonomía de la disciplina se remonta a las aportaciones de los considerados como padres de la victimología. «El trabajo de von Hentig dirigió la atención a la víctima del delito, estableciendo la Victimología como una subdisciplina de la Criminología. La obra de Mendelsohn dirige su atención hacia una Victimología de los derechos humanos, considerándola una disciplina por derecho propio». WALKLATE, S., «Can there be a progressive victimology?», International Review of Victimology, vol. 3, I994, pág. 2.

${ }^{24}$ Morillas Fernandez, D. L, Patro Hernandez, R. Mª, Aguilar Carceles, M. Mº., Victimología: un estudio sobre la víctima y los procesos de victimización, cit., pág.22.

${ }^{25}$ Para Walklate las principales características de esta primera victimología denominada también victimología convencional serían: a) un análisis individualista de las relaciones entre la víctima y el delincuente, b) una tendencia a considerar a la víctima como culpable (victim blaming); c) una tendencia a concentrarse en el delito común. WALKLATE, S., Victimology, Londres, Unwin Hyman, I989, pág. I8.

${ }^{26}$ Resulta altamente significativo que el renovado interés sobre la víctima apareciera en la década de los cuarenta, en plena posguerra mundial, y que el primer simposium internacional se celebrara precisamente en Israel en los años 70. Las atrocidades de la II Guerra Mundial y el descubrimiento de las terribles consecuencias
} 
victimología como «el estudio científico de la extensión, naturaleza y causas de la victimización criminal, de sus consecuencias para las personas envueltas y de las reacciones sociales, en particular de la policía y de los sistemas de justicia criminal, así como de los voluntarios/as y profesionales de ayuda» ${ }^{27}$.

A partir de ese momento, la Victimología fue evolucionando, dejando atrás las primitivas concepciones excesivamente estigmatizadoras para dar paso a una mayor preocupación sobre la víctima de crimen desde un punto de vista social y judicial. Desde esas concepciones más tradicionales se pasó, en los años 80 del siglo $\mathrm{XX}$, a una Victimología denominada como constructivista o realista que se centraba en la necesidad de articular reformas legislativas para el reconocimiento de los derechos las víctimas y en el desarrollo de programas de apoyo psicológico, social y financiero.

Ese sesgo más promocional que adquirió la disciplina, cada vez más relacionado con el activismo social y político, supuso el paso de una Víctimología del acto, más centrada en el análisis y estudio científico de la víctima y del proceso de victimización, a una Victimología de la acción, en la que el estudio de las necesidades de las diferentes víctimas de crimen desde posiciones cercanas al activismo ocupaba un lugar preponderante ${ }^{28}$.

Posteriormente, desarrollos como la denominada Victimología radical o la Victimología crítica permitieron ir un poco más allá al ampliar el concepto de víctima y al ensanchar el campo de interés hacia víctimas tradicionalmente olvidadas como las víctimas de crímenes de cuello blanco y delitos económicos, o de las corporaciones, víctimas de delitos ecológicos, víctimas de guerra y víctimas de crímenes de Estado. Dentro de estas corrientes antihegemónicas resultan especialmente relevantes las aportaciones de la victimología feminista que puso de relieve el hecho de que las mujeres eran especialmente víctimas de algunos delitos muy determinados por cuestiones de género (gendered crimes) colocando en la agenda de investigación victimológica cuestiones tan relevantes como la violencia familiar y doméstica o las agresiones sexuales.

A pesar de las diversas sensibilidades que conviven en su seno y la amplitud del objeto de la misma ${ }^{29}$ así como la pluralidad de abordajes, lo cierto es que el estatus académico de la Victimología no ha dejado de suscitar controversias todo este tiempo. Algunas de ellas se relacionan con ese sesgo cada vez más promocional y activista que, para los críticos, escondería el carácter en el fondo poco científico de muchas de estas aproximaciones $^{30}$.

del Holocausto suponen indudablemente un punto de inflexión en el interés global sobre las víctimas que contribuyó a la formación, poco a poco, de esa nueva sensibilidad.

${ }^{27}$ VAn DiJK, J.J., «Introducing victimology», van DijK, J. J. M., van KAAM, R. G. H. Wemmers, J. (eds.). Caring for crime victims: Selected proceedings of the Ninth International Symposium on Victimology, Amsterdam, August 2529, New York, Criminal Justice Press, I997, pág.6.

${ }^{28}$ NEVES, S., FÁVERo, M., «A vitimologia e os seus percursos históricos, teóricos e epistemológicos», SoFIA, N., FÁvero, M., (coord.) Vitimologia: Ciência e ativismo, Coimbra, Almedina, 20Io, pág. I5.

${ }^{29}$ Según Elena Larrauri las áreas de conocimiento que hoy cobija la victimología serían esencialmente tres: las encuestas de victimización (información sobre víctimas), la posición de las víctimas en el Derecho penal (derechos de las víctimas) y la atención social y asistencial de la víctima (las necesidades de las víctimas). LARrauri PijOAN, E., «Victimología ¿Quiénes son las víctimas? ¿Cuáles sus derechos? ¿Cuáles sus necesidades?», Jueces para la democracia, $\mathrm{n}^{\circ}$ I5, I992, págs.2I-22.

${ }^{30}$ Para Fattah la mejor manera de describir la victimología hoy es como «un movimiento político-ideológico y una profesión de ayuda no muy diferente de la enfermería o el trabajo social», FATTAH, E. A., «Da investigação 
Según Donald Cressey, la Victimología sería un programa no académico, una mezcolanza de ideas, intereses, ideologías y métodos de investigación agrupados más bien arbitrariamente Se caracterizaría por el encontronazo entre dos orientaciones igualmente deseables hacia el sufrimiento humano: la humanística y la científica ${ }^{31}$. Para Elias, que considera algo excesivas estas críticas, ante este panorama, las dos únicas soluciones que puede proponer Cressey son: o bien limitar la Victimología al trabajo de los victimólogos científicos invitando a los humanistas se dediquen al activismo de los derechos humanos o al trabajo social; o bien hacerla desaparecer por completo fusionándose con la Criminología ${ }^{32}$.

Para Ezzat Fatah, un poco en la misma línea aunque menos radical, frente a desarrollos más asistencialistas y politizados, debería apostarse en bien del futuro de la disciplina por el retorno a una Victimología científica, no partidaria y no alineada; una Victimología objetiva, neutra (en términos de raza, género y clase), orientada hacia la investigación y centrada en la teoría. Una Victimología que presta igual atención a los crímenes cometidos contra un individuo y a los cometidos contra grupos y poblaciones enteras, interesada en las victimizaciones cometidas tanto por los poderosos como por los no poderosos. Una Victimología igualitaria que no crea una jerarquía de víctimas. Lo que el autor propone, en definitiva, es la vuelta a una Victimología libre de valores que supere y corrija el foso creado por esta transformación ideológica de la disciplina entre victimólogos científicamente orientados y victimólogos ideológicamente comprometidos y centrados en la acción ${ }^{33}$.

También para Andrew Karmen la objetividad es clave en el desarrollo del estudio científico de la víctima ${ }^{34}$ aunque achaca esa cierta mala fama injustificada de la Victimología actual a la confusión, a veces interesada, entre Victimología y victimismo ${ }^{35}$. Porque la solidez de la disciplina, su carácter científico, la necesaria objetividad y el rigor de las investigaciones y trabajos, no tiene por qué excluir necesariamente el carácter de ciencia aplicada de la misma lo que la llevaría a aportar conocimiento para la mejora real de la situación de las víctimas del delito ${ }^{36}$. Como advierte Tony Peters, la política victimológica en el futuro «debe dejar lugar a proyectos diversificados y bien inspirados de los que se puedan sacar las conclusiones necesarias para la organización de un servicio centrado sobre las

ao ativismo, da academia ao partidarismo e o resultante empobrecimento da Vitimologia», SOFIA, N., FÁVERO, M., (coord.), Vitimologia: Ciência e ativismo, Coimbra, Almedina, 20ı, pág. 79.

${ }^{31}$ CRESSEY, D. «Research implications of conflicting conceptions of victimology», FATTAH, E.A. (ed.) Towards A Critical Victimology, New York, St. Martin’s Press, I992, págs.57-73.

${ }^{32}$ Elias, R, «Paradigms and Paradoxes of Victimology», Sumner, C., Israel, M., O'Connell. M., Sarre R., (eds.), International victimology: selected papers from the 8th international symposium, Canberra, Australian Institute of Criminology, I996, pág, 9.

${ }^{33}$ FATTAH, E. A., «Da investigação ao ativismo, da academia ao partidarismo e o resultante empobrecimento da Vitimologia», cit., pág. 72.

${ }^{34}$ Karmen, A., Crime Victims. An introduction to Victimology, Belmont, Wadsworth, 20IO, págs. 4-Io.

${ }^{35}$ Según Josep Maria Tamarit, ell victimismo «aparece a menudo asociado a actitudes de hipersensibilidad y sobreactuación por parte de representantes de víctimas o de colectivos sociales. Estos se erigen en intérpretes, autorizados o no, de sus opiniones y sentimientos y tienden a entender o a expresar como agravio o burla a las víctimas toda decisión que no se corresponda con sus expectativas.» TAMARIT SumAlla, J.M., «Paradojas y patologías en la construcción social, política y jurídica de la victimidad», InDret. Revista para el análisis del Derecho, $\mathrm{n}^{\circ}$ I, 20I3, pág.I9 (disponible en http://www.indret.com/pdf/940.pdf; fecha de consulta: 08.09.20I4).

${ }^{36}$ Karmen, A., Crime Victims. An introduction to Victimology, cit., pág. I4. 
necesidades reales de las víctimas. Esto supone que se deje al mismo tiempo suficiente lugar a la investigación científica que debe analizar y evaluar esos desafíos» ${ }^{37}$.

De acuerdo con Rorbert Elias, que asume la Victimología más bien como una cuestión de derechos humanos, los victimólogos y los defensores de las víctimas deben trabajar conjuntamente buscando un punto de encuentro común ${ }^{38}$. Nada impediría desarrollar con rigor científico una victimología que siga defendiendo firmemente los principios garantistas asociados con el Derecho penal al tiempo que trata de buscar acomodo a los intereses de las víctimas y, al tiempo, visibilice determinados colectivos vulnerables desde un concepto inclusivo y amplio pero riguroso científicamente de victimización.

Es evidente que, como recuerda Tamarit Sumalla, en nuestras sociedades contemporáneas, tan obsesionadas por la seguridad y el riesgo, el tratamiento de la víctima presenta, en no pocas ocasiones, patologías ${ }^{39}$. El interés social y político en relación con las víctimas es legítimo aunque no deba ser, desde luego, el único interés a tener en cuenta en el desarrollo de las políticas criminales ${ }^{40}$. La atención adecuada de las mismas constituye un rasgo necesario en cualquier sociedad que aspire a constituirse como una sociedad decente. Como Andrew Karmen recomienda, en este contexto, «la Victimología debe configurarse como un desafiante, equilibrado, iluminador, constructivo y relevante campo de estudio que se centra en un problema muy antiguo pero desde un nuevo y refrescante ángulo» ${ }^{4 \mathrm{~T}}$.

Tras este contextual recorrido, necesariamente breve y sucinto, por el nacimiento y desarrollo de la Victimología, pasaremos a ocuparnos más directamente de esa lectura en clave victimológica que la película de Bergman elegida nos sugiere.

\section{Una posible guía de lectura desde la Victimología}

La lectura de «El manantial de la doncella» (Jungfrukällan, I960) que aquí proponemos parte de elementos explícitos en la trama argumental pero se extiende también hacia cuestiones que están sugeridas o simplemente conectadas con elementos presentes

${ }^{37}$ Peters, T., «Consideraciones teóricas sobre la victimología», Cuaderno Vasco de Criminología, nº 2, I988, pág.I33.

${ }^{38}$ Desde su perspectiva, el problema «no es tanto que haya demasiada política o ideología en la Victimología, sino que esta sea la política e ideología equivocada, filosofías que han fracasado miserablemente en la reducción de la victimización y en la tarea ayudar a las víctimas. La superación de este problema no se basa en el rechazo de la ideología, sino más bien en dedicarnos más plenamente a la búsqueda de una política que funcione. Si no elegimos la política que queremos, la política elegirá por nosotros; de hecho, ya lo ha hecho». ELIAS, R, «Paradigms and Paradoxes of Victimology, International Victimology», cit., pág. I5.

${ }^{39}$ Tamarit Sumalla habla de diversas patologías sociales respecto de las víctimas: el pensamiento dicotómico (que contrapone sin matices a las víctimas inocentes y a los victimarios culpables), la percepción distorsionada de ciertas víctimas y formas de victimización, la politización (como ha ocurrido en España en cierta medida con las víctimas del terrorismo o de la represión franquista), el victimismo (que analizábamos más arriba) y la diferenciación y jerarquía (de las que hablaremos un poco más adelante). TAMARIT SumALLA, J.M., «Paradojas y patologías en la construcción social, política y jurídica de la victimidad», cit., págs. I2-20.

${ }^{40}$ Sobre todo si ese interés, como suelen hacer ciertos grupos, se presenta únicamente como la necesidad de más punitivismo para considerar que la administración de justicia se toma realmente en serio a las víctimas. Esto se corresponde a la idea bastante extendida de que los derechos de las víctimas solo se protegen si se les niega sus derechos a los agresores. Lo cual genera «un juego de suma cero basado en la dudosa presunción de que las víctimas solo ganan si los agresores pierden» ELIAS, R, «Paradigms and Paradoxes of Victimology», cit., pág. 2I.

${ }^{41}$ Karmen, A. Crime Victims. An introduction to Victimology, cit., pág.I4. 
en la película. Articularemos nuestro análisis en tres bloques diferentes, cada uno centrado en uno o varios personajes y en una emoción determinada.

Una parte importante de estas reflexiones se focalizará en las funciones del Derecho penal en relación con varias cuestiones conectadas con el papel de las víctimas. Por ello no es de extrañar que incluyamos en nuestro análisis referencias a las emociones ya que, como recuerda María José Bernuz, uno de los sectores más emocionales dentro del ordenamiento jurídico es, precisamente, el Derecho penal ${ }^{42}$. Todo es emoción y sentimiento en él: tanto los procesos de su conformación como Derecho, como la realización de su contenido y la determinación de sus consecuencias ${ }^{43}$. Por eso no deja de ser paradójico que aceptemos sin demasiados problemas que el Derecho regula la vida pero nos cueste asumir que ese mismo Derecho tenga algo que ver con las emociones inherentes a la misma. Y esa pretendida neutralidad y asepsia emocional aún resulta más llamativa en el ámbito concreto del Derecho penal puesto que éste «intenta resolver situaciones conflictivas de las personas que, entre otras cosas, ven afectada su salud mental y emocional por la comisión de un delito» ${ }^{44}$.

\section{IV.I. La compasión y la doncella}

La primera parte de nuestro análisis gira en torno a la figura de la doncella y su representación como víctima ideal. La emoción central que analizaremos aquí será la compasión. De todas estas emociones sobre las que reflexionaremos esta es la que resulta más pública, más propia de la comunidad y, por lo tanto, más política.

A pesar de la belleza de la escena final del manantial y sus numerosas resonancias simbólicas, la viga maestra de toda la película es, desde mi punto de vista, la escena de la violación y posterior asesinato de la doncella en un claro del bosque. Se trata de una de los momentos más brutales de toda la obra de Bergman, que siempre fue un cineasta de la crueldad, y constituye una de las representaciones más efectivas del horror de la violencia en la historia del cine. La escena marca el tono de la obra hasta el punto de que amenaza casi con desequilibrarla ${ }^{45}$.

Parte del efecto que esa escena produce en el espectador tiene que ver con elementos expresivos utilizados por el director ${ }^{46}$. Pero también con el hecho de que

\footnotetext{
${ }^{42}$ Bernuz Beneitez, $\mathrm{M}^{\circ}$.J., «El sentido de las emociones en el Derecho penal», Nuevo Foro Penal, $\mathrm{n}^{\circ}$ 8I, juliodiciembre, 2013, págs. 228-229.

${ }^{44}$ Bernuz BeneiteZ, $M^{\circ}$.J., «El sentido de las emociones en el Derecho penal», cit., pág. 2II.

${ }^{45}$ Como agudamente hace notar Alexandra Hellen-Nicholas, coincidiendo en parte como veíamos más arriba con las intenciones expresadas por el propio Bergman, aunque en la superficie la película parece centrarse en el viaje espiritual del caballero, lo que perdura en el espectador es el haber sido testigo de la espantosamente naturalista muerte de la doncella Karin. «Es el shock, el terror, la confusión y el silencio sofocante de la agresión lo que deja una huella más indeleble en el espectador: el manantial del título quizás pueda calmar a Töre, el caballero traumatizado, pero el espectador probablemente pensará que hay algunas cosas que no pueden ser tan fácilmente arrastradas por la corriente». Hellen-Nicholas, A., «Silence and Fury: Rape and The Virgin Spring», Screening the past», $\mathrm{n}^{\circ}$ 29, 20I0, pág. 6, (disponible en:

http://tlweb.latrobe.edu.au/humanities/screeningthepast/28/rape-and-the-virgin-spring.html; fecha de consulta: I0.09.20I4).

${ }^{46}$ Entre otros: el silencio ominoso en toda la escena, los opresivos primeros planos, la forma en la que la doncella muere a garrotazos, la destrucción de los cirios, la contemplación pasiva y horrorizada del menor (que después vomita) y la naturaleza omnipresente, salvaje, misteriosa e indiferente. Cuando todo ha acabado, comienza suavemente a nevar. Algunos críticos reprocharon en su momento a Bergman que estaba estilizando peligrosamente un acto de violencia brutal, haciéndolo bello.
} 
consideramos y asumimos que la doncella Karin es, siguiendo la clasificación de Mendelsohn, una víctima totalmente inocente ${ }^{47}$. Una víctima que, en nuestra representación social de la misma, no merecía la agresión y la muerte en ningún caso. La escena nos lleva, si bien de una forma brutal, a sentir compasión por ella y también por el grupo de personas más cercano, que son víctimas secundarias.

La doncella de Bergman se presenta, al menos en apariencia, como una encarnación casi perfecta de la víctima ideal que teorizó Nils Christie ${ }^{48}$. Tal y como recuerda Sandra Walklate, en este análisis tradicionalmente la victima ideal es la mujer joven, que, saliendo a hacer el bien, es atacada por un hombre desconocido, físicamente mucho más fuerte que ella ${ }^{49}$. Es decir, el prototipo encaja casi sin fisuras en el personaje de Karin, la doncella: una mujer joven (y pura) que va a realizar una buena acción (llevar piadosamente una ofrenda de cirios a una iglesia) y que se ve brutalmente atacada por alguien al que físicamente no puede resistirse (en este caso, dos caminantes que la acaban violando y asesinando). En la representación social, este ideal de víctima, totalmente inocente, atacada por un agresor brutal y despiadado, merece toda nuestra compasión y moviliza un considerable apoyo social.

En definitiva, la concepción de la víctima ideal captura las condiciones sociales bajo a las cuales no solo se otorga a alguien el estatus de víctima, sino también se determina si lo merece o $\mathrm{no}^{50}$. Porque, como algunos autores destacan ${ }^{5 \mathrm{I}}$, el poder cultural de este concepto de víctima ideal conlleva una jerarquización: en lo más alto de la estima social se colocarían las víctimas ideales (e idealizadas) objeto de compasión y de apoyo porque son percibidas como vulnerables e inocentes. A continuación, se colocan otras víctimas que, por diversas circunstancias, aparecen cada vez como menos merecedoras de esos sentimientos y, en consecuencia, del apoyo que éstos pueden movilizar en la comunidad pudiendo, las menos valoradas, llegar a ser prácticamente invisibles e ignoradas socialmente ${ }^{52}$.

Como vemos en todo este proceso de representación social de la víctima el sentimiento de compasión está muy presente. Partiremos para introducir el tema en nuestro propio análisis de las tesis sobre la compasión elaboradas por Martha C.

\footnotetext{
${ }^{47}$ Mendelsohn, B., «Une nouvelle branche de la science bio-psycho-sociale: la victimologie», cit.

${ }^{48}$ Según el autor la victima ideal es débil y vulnerable, estaba realizando una actividad respetable cuando el crimen aconteció, no puede ser culpada por estar donde estaba cuando el crimen ocurrió, el agresor era grande $y$ perverso y era desconocido por la víctima. CHRISTIE, N. «The ideal victim», FATTAH, E.A. (ed.), From crime policy to victim policy, London, Macmillan, I986, págs. I7-30.

49 Walklate, S., «Reframing criminal victimization: Finding a place for vulnerability and resilience», Theoretical Criminology, I5(2), 20II, pág.I83.

${ }^{50}$ WALKLATE, S., «Reframing criminal victimization: Finding a place for vulnerability and resilience», cit., pág.I83.

si Carrabine, E., Inganski, P., Lee, M., Plummer, K., South, N., Criminology: A Sociological Introduction, London, Routledge, 2004, pág.II7.

${ }^{52}$ Como concluye Tamarit Sumalla, «los procesos de atribución de la victimidad están caracterizados por su selectividad. La idealización lleva a la jerarquización, en la medida en la que las diferentes clases de víctimas responden de modo distinto a la expectativa. La solidaridad de la comunidad, el sentimiento de deuda con la víctima, se gradúa en función del sacrificio que la víctima ha soportado por la comunidad». Para el mencionado autor, en España, «la diferenciación y la jerarquía han alcanzado cotas muy elevadas, lo cual se hace evidente al no existir un estatuto jurídico de la víctima sino regímenes legales muy diferenciados para las diversas categorías de víctimas (de terrorismo, violencia de género, etc...)» TAMARIT SumALLA, J.M., «Paradojas y patologías en la construcción social, política y jurídica de la victimidad», cit., pág.I9.
} 
Nussbaum ${ }^{53}$. La filósofa norteamericana define la compasión como «una emoción dolorosa orientada hacia el sufrimiento grave de otra criatura o criaturas $»^{54}$. Se compondría de cuatro pensamientos: el pensamiento de gravedad, el pensamiento de la no culpabilidad, el pensamiento de la similitud de posibilidades, y finalmente, el pensamiento eudemónico.

Cuando alguien experimenta compasión piensa que la otra persona está sufriendo de un modo importante y no trivial. Este pensamiento de gravedad estaría claramente plasmado en la película en ciertos elementos de la brutal escena de la violación y el asesinato. El personaje de Ingeri, que acompaña a la doncella y contempla el crimen, siente compasión a pesar de la animadversión personal que siente por Karin y de no impedir el resultado fatal. Bergman representa visualmente este sentimiento con una piedra que Ingeri sujeta y que deja caer al suelo. Y nosotros, como si estuviéramos agazapados tras los matorrales con Ingeri, también contemplamos la gravedad de lo que está ocurriendo en todo su horror y ello nos conmueve y nos lleva hasta la compasión, aunque sea vicariamente y como meros espectadores de la tragedia.

El segundo pensamiento tendría que ver con la no culpabilidad. En general no sentimos compasión si pensamos que el problema o la dificultad que padece la persona han sido escogidos por ella misma. Y aunque la propia Nussbaum reconoce que este pensamiento no es un elemento conceptual en todos los casos, puesto que hay formas de compasión que no implican valoración alguna de la responsabilidad, sí está presente en las formas más comunes de la compasión humana adulta ${ }^{55}$. Desde luego así es cuando hablamos de la representación social de las víctimas de delitos graves. Todo ello presenta además una fuerte conexión con la primera ola de la Victimología, con sus clasificaciones victimales basadas en la responsabilidad de la víctima, los desarrollos teóricos que exploraban la precipitación victimal (victim precipitation) y también con conceptos de larga tradición en el campo victimológico, como el ya analizado de victima ideal de Christie.

El hecho de que pensemos que la doncella es totalmente inocente, una víctima ideal, es lo que nos permite sentir compasión por ella porque si supiéramos (o creyéramos) que ha tenido algún tipo de responsabilidad en el resultado fatal, o lo precipitó de alguna manera con su comportamiento, ese sentimiento quedaría probablemente inhibido o, al menos, matizado. El problema es que esa construcción cultural de la víctima ideal no deja de ser difícil de mantener en la vida real, que suele ser mucho más compleja y sujeta a matices. La doncella, que en una primera visión nos parecía un ejemplo casi perfecto de víctima ideal, ¿realmente lo es?

Para responder a esta pregunta, debemos tener en cuenta dos cuestiones esenciales: que se trata de una mujer y que es víctima de una agresión sexual. Estos dos elementos o circunstancias son determinantes a la hora de configurar ese estatus de respetabilidad de la víctima.

El caso de violencia sexual que muestra la película puede ser abordado desde un punto de vista histórico (la evolución del tratamiento de este tipo de delitos desde la edad media hasta la actualidad) pero haciendo hincapié en ciertas continuidades todavía muy

\footnotetext{
${ }^{53}$ Nussbaum, M.C., Emociones políticas, cit., págs. I75 ss.

${ }^{54}$ Nussbaum, M.C., Emociones políticas, cit., pág.I73.

${ }^{55}$ Nussbaum, M.C., Emociones políticas, cit., pág. I76.
} 
presentes en la representación social de estas víctimas ${ }^{56}$. Los trabajos historiográficos muestran como en la época medieval y moderna el uso de la fuerza es el primer elemento constitutivo de este tipo de crímenes, mientras que el segundo consiste en que dicho acto ha ocasionado la pérdida de la virginidad de la agredida ${ }^{57}$. Aunque en la actualidad se estaría evidentemente lejos de esa arcaica visión sobre este tipo de delitos que hoy englobaríamos en el grupo de los delitos contra la libertad $\operatorname{sexual}^{58}$, no deja de resonar aún hoy en día un eco de esa concepción primitiva ${ }^{59}$. Por eso para el feminismo, la forma de abordar la cuestión de los crímenes sexuales por parte de la Victimología, al menos en su vertiente más tradicional y sobre todo en la primera la $^{60}$, fue siempre una cuestión muy controvertida ${ }^{6 \mathrm{r}}$.

\footnotetext{
${ }^{56}$ «En época medieval y moderna los documentos nunca emplearon el término violación para referirse a la agresión sexual, sino los de conocer carnalmente, dormir con una mujer, echarse carnalmente con ella, etc. Todas ellas son expresiones que vienen acompañadas por los términos por fuerza o contra su voluntad, indicativos de que el delito ha existido no por el mantenimiento de una relación sexual ilegítima, sino por haber sido ésta llevada a cabo contra la voluntad de la víctima y mediante el uso de la fuerza física o la amenaza». CóRDOBA DE LA LLAVE, R., «Consideraciones en torno al delito de agresión sexual en la Edad Media», Clio y Crimen, $\mathrm{n}^{\circ}$ 5, 2008, pág.I90.

${ }^{57}$ «En ese caso la documentación añade siempre que el agresor ha corrompido o ha habido la virginidad de la víctima, lo cual fue sin duda una circunstancia agravante, por cuanto a la fuerza se añadió la deshonra para la mujer y su grupo familiar». CóRDOBA DE LA LLAVE, R., «Consideraciones en torno al delito de agresión sexual en la Edad Media», cit., pág. I90.

${ }^{58}$ La propia exposición de motivos de la reforma del Código Penal español del 95 (Ley Orgánica Io/I995, de 23 de noviembre, del Código Penal, BOE, $\mathrm{n}^{\circ}$. 28I, 24 de noviembre de I995) señalaba al respecto que «se pretende con [esta reforma] adecuar los tipos penales al bien jurídico protegido, que no es ya, como fuera históricamente, la honestidad de la mujer, sino la libertad sexual de todos. Bajo la tutela de la honestidad de la mujer se escondía una intolerable situación de agravio, que la regulación que se propone elimina totalmente». Bajo la rúbrica Delitos contra la libertad y la indemnidad sexuales (arts. I78 a I94), como recuerda Ariadna Aguilera, el Código Penal Español considera como punibles tanto los atentados a la libertad e integridad sexual que se lleven a cabo con violencia o intimidación como aquellos que tienen lugar sin mediar consentimiento. Esto supone un avance respecto de anteriores regulaciones que tan sólo tipificaban las agresiones sexuales y por tanto el uso de fuerza o intimidación Se equipara, además, la ausencia de consentimiento al supuesto en que el responsable del delito lo ha obtenido prevaliéndose de una situación de superioridad manifiesta que coarta la libertad de la víctima (art. I8I.3). No obstante, la misma autora considera evidente a partir del análisis de pronunciamientos judiciales recientes «cómo es el punto de vista masculino el que condiciona la valoración de qué conductas son más graves y merecen una pena superior y al hacerlo priva a las mujeres, que son las que mayoritariamente sufren tales vejaciones y cuya libertad sexual está en juego, de la posibilidad de llevar al derecho su experiencia. Los delitos contra la libertad e integridad sexual están basados en la idea de que es más lesivo el uso de la violencia e intimidación que el hecho de actuar sin el consentimiento de la víctima». AGUILERA RulL, A., «La actualidad del análisis feminista del derecho al hilo de pronunciamientos judiciales recientes», Anales de la Cátedra Francisco Suárez, n 46, 2012, págs.197-200.
}

${ }^{59}$ De acuerdo con Ricardo Córdoba de la Llave: «Un (...) rasgo que conecta la violación de época medieval con la que se sigue produciendo en nuestros días es la prevención de las justicias ante el posible engaño de la parte ofendida, lo que conlleva la necesidad impuesta a la víctima de evidenciar de manera pública y nítida el hecho. Ya nos hemos referido a la necesidad de acreditar que se era moza virgen $y$ de buena fama, o sea, de mantener una ordenada conducta moral y sexual, para hacer creíble una denuncia por violación; pero además de ello, en tiempos medievales se elaboró toda una legislación sobre el modo de proceder que debían tener las mujeres que hubieran sufrido una agresión sexual para hacer creíble ante la justicia la comisión del delito y su falta de consentimiento a la relación». CóRDOBA DE LA LLAVE, R., «Consideraciones en torno al delito de agresión sexual en la Edad Media», cit., pág. I97.

${ }^{60}$ Hay que pensar, como punto de inflexión, en el polémico trabajo de Amir sobre la violación desde un enfoque relacionado con el papel de precipitación del acto por parte de la víctima. Este trabajo fue muy criticado desde el feminismo no solo desde el punto de vista metodológico sino también ideológico al fomentar una culpabilización de las víctimas mujeres y fomentar el estereotipo o bien de mujer provocadora o bien de una víctima que se asocia a la pasividad y la debilidad supuestamente femeninas. AmIR, M., Patterns of Forcible Rape, Chicago, Chicago University Press, I97I.

${ }^{61}$ WALKLATE, S., «Sexual violence against women: Still a controversial issue for victimology?», International Review of Victimology, $\mathrm{n}^{\circ}$ 20, 2014, pág. 73. 
La doncella bergmaniana Karin, desde esta perspectiva culpabilizadora, podría no ser estrictamente la víctima ideal que generara nuestra compasión sin trabas. En las primeras escenas la vemos remolonear tratando de no tener que entregar las velas en la lejana iglesia (quizás no sea tan piadosa, por lo tanto); discute con su madre negociando, como cualquier adolescente, el que le dejen llevar su ropa nueva y la melena suelta (tal vez no se trate de una recatada doncella sino de una joven vana y presumida); y, una vez se adentra en el bosque (es decir, yendo por donde no debía) no duda en trabar un contacto, que es casi flirteo, con los agresores compartiendo incluso el alimento (esto es, precipitando el resultado fatal).

Aunque este juicio, poco compasivo, sobre la doncella puede resultarnos perturbador no estaría muy alejado en intenciones del que algunas mujeres víctimas de agresiones sexuales soportan algunas veces por parte del propio sistema de justicia o de la comunidad. Lo que remite a una de las formas de victimización que es objeto preferente del campo de análisis de la Victimología: la victimización secundaria ${ }^{62}$. La victimización secundaria abarca las relaciones de la víctima con el sistema jurídico-penal, estudia en qué medida la relación de la víctima con el sistema de justicia ha aumentado la victimización ${ }^{63}$.

Además hay otros dos conceptos clave en relación con el estudio de las víctimas que afectan a la percepción social de la misma: vulnerabilidad y resilencia ${ }^{64}$. La mayoría de las clasificaciones victimales recogen el concepto de víctima especialmente vulnerable ${ }^{65}$. La doncella de la película sería, según la mayoría de estos análisis, una víctima vulnerable sobre todo por su juventud, por el hecho de ser mujer. Aunque persiste la duda de si, en determinados casos (sobre todo relacionados con las mujeres) este énfasis en la vulnerabilidad no puede propiciar un cierto desapoderamiento de las víctimas.

Es evidente que, como construcción social, la imagen de las víctimas no es igual en todos los supuestos: por ejemplo, no es socialmente percibida de la misma manera la agresión sexual y la muerte de una prostituta que la de una joven adolescente como la de la película $^{66}$. En definitiva el pensamiento de la no culpabilidad es clave cuando estamos hablando de compasión respecto de las víctimas de crimen.

${ }^{62}$ El término de victimización secundaria fue acuñado por Khüne para referirse a todas las agresiones psíquicas que la víctima recibe en su relación con los profesionales de los servicios sanitarios, policiales, o judiciales (interrogatorios, reconstrucción de los hechos, asistencia a juicios, identificaciones de acusados, lentitud y demora de los procesos, etc), así como, los efectos del tratamiento informativo del suceso por parte de los medios de comunicación. KÜHNE, H.H., «Kriminologie: Victimologie der Notzucht», Juristische Schulung, $\mathrm{n}^{\circ}$ 5, I986, págs. 388-394.

${ }^{63}$ Giner Alegría, A., «Aproximación psicológica de la victimología», Revista Derecho y Criminología, $\mathrm{n}^{\circ} \mathrm{I}$, 20II, págs. 25-56, pág. 46 .

${ }^{64}$ Para Rutter la resilencia es un conjunto de procesos sociales y psíquicos que posibilitan el desarrollo de una vida sana en un ambiente que no lo es. RUTTER, M., «Psychosocial resilience and protective mechanisims». American Journal of Ortho psyquiatry, $\mathrm{n}^{\circ} 57$ (3), I987. Muy gráficamente Giligan la define como la capacidad de «hacer las cosas bien a pesar de la experiencia adversa». Gilligan, R., «Adversity, Resilience and Young People: The Protective Value of Positive School and Spare Time Experiences»., Children and Society, $n^{\circ}$ I4, 2000.

${ }^{65}$ Desde las primitiva clasificación victimal de von Hentig que comienza a introducir ese concepto de víctima vulnerable hasta los últimos desarrollos la literatura sobre el tema resulta muy abundante como para ser reseñada aquí. No obstante puede encontrarse una interesante reflexión crítica al respecto en WALKLATE, S., «Reframing criminal victimization: Finding a place for vulnerability and resilience», cit., págs. I79-I94.

${ }^{66}$ «En la parte baja de esta jerarquía [de víctimas] estarían las personas sin hogar, los drogadictos, las prostituta que hacen la calle: todos aquellos para quienes su estilo de vida los hace propensos a la victimización (son vulnerables pero se les niega la condición de víctimas); y en la parte superior estarían las mujeres mayores víctimas de delitos violentos (mucho menos propensas a este tipo de delincuencia, pero que se perciben como 
Continuando con las tesis de Nussbaum, el siguiente pensamiento constitutivo de la compasión sería el de la similitud de posibilidades. La persona que siente compasión suele pensar que aquel que sufre se le parece y tiene posibilidades en la vida similares a las suyas $^{67}$. Desde este punto de vista, como pasa en muchos de los casos reales parecidos al de la película que son objeto de un tratamiento mediático intensivo, somos capaces, como espectadores o como opinión pública, de colocarnos en una posición similar a la de la doncella, sus familiares y allegados o cualquier otra víctima en el mundo real de un acto semejante de la que tengamos conocimiento. Entendemos la pérdida de la vida en un acto violento de este tipo como absurda al tiempo que empatizamos con el terrible dolor y sentimiento de pérdida de los familiares y allegados. Pero ese tratamiento mediático de muchos de estos crímenes, como veremos después con más detalle, puede fácilmente escorar hacia la manipulación de la opinión pública pues suele utilizarse un lenguaje excesivamente emocionalizado que acaba por justificar y servir de plataforma a peticiones de mano dura que se centran únicamente en los aspectos retributivos de la pena.

Finalmente, el último pensamiento al que se refiere Nussbaum sería el pensamiento eudemónico. Este pensamiento colocaría a la persona o personas que sufren entre las partes importantes de la vida de la persona o personas que siente la emoción compasiva. Sería como decir «estas personas cuentan para mí; están entre mis objetos y proyectos más importantes» ${ }^{68}$. Aunque estemos hablando de una película, su visionado nos sirve para reflexionar sobre la compasión que podemos sentir sobre víctimas reales. Esto es, víctimas de las que tenemos conocimiento habitualmente a través de los medios de comunicación, o que pueden formar parte de nuestro círculo de allegados más o menos próximo o, en mucha menor medida, que conozcamos a través de los diferentes datos y análisis científicos sobre victimización

En este último pensamiento residiría, en esencia, el carácter más político de la compasión dirigida hacia las víctimas. La atención hacia determinadas personas que sufren, en este caso las víctimas de delito, es inestable y fácil de desviar hacia nosotros mismos y hacia nuestro entorno inmediato. Por eso, uno de las tareas de cualquier uso político de la compasión consistiría en crear unas estructuras estables de interés por los demás que extiendan ampliamente ese uso ${ }^{6}$. De aquí se derivaría la necesidad de que los poderes públicos reconozcan y garanticen derechos de las víctimas y fomenten el apoyo y la atención a las mismas con estructuras y políticas eficientes y eficaces.

Es decir, el destino de las victimas debe ser una preocupación para una sociedad decente que aspire a la justicia. Con todo, este proceso no debe dejar nunca de estar sujeto a la crítica para evitar que ese interés legítimo de las víctimas se instrumentalice justificando políticas criminales cada vez más punitivistas o se limite a determinados tipos de víctimas

vulnerables y a las que, socialmente, la condición de víctimas se les asigna muy fácilmente)». WALKLATE, S., «Reframing criminal victimization: Finding a place for vulnerability and resilience», cit., pág. I83.

\footnotetext{
${ }^{67}$ Nussbaum, M.C., Emociones políticas, cit., pág. I77.

${ }^{68}$ Nussbaum, M.C., Emociones políticas, cit., pág. I78.

${ }^{69}$ Nussbaum, M.C., Emociones políticas, cit., pág. I79.
} 
excluyendo e invisibilizando a otras o perpetúe desde la acción o de la capacidad de promoción de los poderes públicos la jerarquización de las mismas ${ }^{7 \circ}$.

La atención y preocupación pública por las víctimas debe adaptarse a sus necesidades reales entre otras razones porque no todos los efectos de la victimización son iguales. Podemos encontrar casos donde incluso el impacto de esa victimización pasa inadvertido de aquellos otros donde la cronicidad hace que el propio suceso condicione grandemente la vida del sujeto ${ }^{71}$. Como es lógico, dependen del tipo de crimen, de las características personales, sociales y psicológicas de la víctima y también de la existencia de una fuerte red de apoyo social y comunitario. Si nos centramos en los efectos sobre las víctimas de delitos graves, estos son numerosos desde el punto de vista tanto físico como psicológico $^{72}$. En consecuencia, los procesos de atención a las víctimas desde diversos ámbitos deben ser sensibles a todas estas cambiantes circunstancias ${ }^{73}$.

Ese proceso de atención a la víctima para que, en la medida de lo posible, recupere la situación anterior a haber sufrido la victimización se denomina proceso de desvictimización. Es un proceso complejo y multicausal, caracterizado por la intervención de muy diversos factores, y sobre el cual se sustentan la construcción de nuevas políticas de apoyo y asistencia a los sujetos damnificados por los actos criminales. Intervienen en el mismo muchos profesionales y especialistas de diversos ámbitos (psicólogos, médicos, operadores jurídicos, policía, etc) que abordan el proceso desde una perspectiva integral y multidisciplinar. Para Caravaca Llamas este complejo proceso pretende, de un lado «fundamentar y justificar una actuación específica de la Política Social para las víctimas; pero por otro busca normalizar, en la medida de lo posible, la situación de las mismas en el conjunto de la sociedad, eliminado toda posibilidad de estigmatización, de instalación crónica en la victimización, o la generación de una comunidad de víctimas cerrada en sí misma» ${ }^{74}$.

Implica, por lo tanto, como uno de sus elementos fundamentales, la restitución o resarcimiento del impacto o secuelas que haya podido generar el hecho criminal en la

$7^{70}$ Debemos ser siempre cuidadosos porque la compasión se puede confundir con el paternalismo o la superioridad. Como recuerda Richard Sennet, «la piedad puede generar menosprecio; la compasión puede estar ligada a la desigualdad. Para que la compasión sea operativa tal vez haya que atenuar el sentimiento, tratar a los otros con frialdad». Es decir, debe estar unida a un concepto básico como es el del respeto. Para evitar estos malentendidos deberíamos hablar el lenguaje de los derechos, al menos aparentemente objetivo, que, aunque se sustente inevitablemente en emociones, sepa sortear las posibles trampas del sentimentalismo. SENNET, R., El respeto, Barcelona, Anagrama, 2003, pág.33.

${ }^{71}$ Morillas Fernandez, D.L., Patro Hernandez, R. Mª., Aguilar Carceles, M. Mº, Victimología: un estudio sobre la víctima y los procesos de victimización, cit., pág. I23.

${ }^{72}$ Para un análisis sobre los principales efectos de la violencia puede consultarse por ejemplo a HERRERO Alonso, C., Garrido Martín, E., «Los efectos de la violencia sobre sus víctimas», Psicothema, vol. I4, 2002, págs.IO9-II7.

${ }^{73}$ Según Caravaca, en el caso español, «estos campos de atención a las víctimas perfilan ya una acción genérica de la Administración social española respecto a las víctimas, a nivel nacional y autonómico, desarrollada a través de las siguientes actuaciones: a) Atención psicosocial (desde la atención personalizada hasta la rehabilitación moral y/o conmemoración). b) Garantías legales y policiales de no repetición, prevención y sanción social. c) Mediación penal. d) Apoyo económico y social (desde las prestaciones asistenciales y contributivas hasta el apoyo mutuo de carácter asociativo)».CARAVACA LLAMAS, C. «Política Social y asistencia a las víctimas de delitos en España: del reconocimiento legal a la protección social», Contribuciones a las Ciencias Sociales, marzo 20II, pág.3 (disponible en: www.eumed.net/rev/cccss/II/; fecha de consulta: 08.09.20I4).

${ }^{74}$ Caravaca Llamas, C. «Política Social y asistencia a las víctimas de delitos en España: del reconocimiento legal a la protección social», cit., pág.5. 
figura de la víctima. Esta reparación de la víctima, en un sentido amplio, es uno de los objetivos fundamentales, sino el que más, de la Victimología, sobre todo en sus desarrollos más recientes, como veíamos al hablar de la evolución histórica de la disciplina ${ }^{75}$.

¿Qué papel ocupa el Derecho en todo este proceso? Para responder a esta pregunta me parece interesante partir de la aseveración de Antonio Madrid según la cual el derecho no puede ser comprendido al margen del sufrimiento. El Derecho, no solo el penal, actúa históricamente como un instrumento determinante en el tratamiento de los daños que acaecen en la vida en común ${ }^{76}$. En la respuesta social relacionada con la víctima de crimen, donde existe mucho dolor y sufrimiento sobre todo en los casos de victimización más graves, el recurso al Derecho penal y la justicia criminal es un elemento importante, aunque no necesariamente el único.

A través de sus transformaciones, más allá del análisis científico de la participación de la víctima en los hechos y la integración de la misma en la teoría jurídica del delito de la que se ocupa la Victimodogmática ${ }^{77}$, se han ido reconociendo, a partir del auge de las nuevas perspectivas abiertas por la moderna Victimología, una serie de derechos de la víctima en el proceso, fomentando su mayor protagonismo ${ }^{78}$.

Como señala Mauricio Martínez, en una perspectiva garantista del Derecho penal, «las víctimas asumen un rol importante históricamente negado por el sistema penal tradicional que siempre ha tratado de presentar la criminalidad como problema de orden público, es decir que concierne primero al poder público constituido. Ello no significa

\footnotetext{
${ }^{75}$ Morillas Fernandez, D. L, Patro Hernandez, R. Mª, Aguilar Carceles, M. Mº., Victimología: un estudio sobre la víctima y los procesos de victimización, cit., págs. I23-I24.

${ }^{76}$ Según Madrid el Derecho aborda el sufrimiento a través de tres operaciones: la representación (mediante la que se forma la idea jurídica de sufrimiento), la interpretación de normas y hechos (mediante la que se precisa la cuestión a resolver y la resolución del caso) y la decisión (que busca resolver la situación). «Sin la representación jurídica del sufrimiento sería imposible crear normas que hablasen del dolor y de qué tratamiento darle. Sin interpretación del derecho no saldrían de las estanterías para ser aplicadas a los casos concretos. Sin la decisión, ni se establecerían qué sufrimientos son relevantes - no todos los sufrimientos adquieren el mismo estatus jurídico - ni se producirían efectos en la vida de las personas». MADRID, A., La política y la justicia del sufrimiento, Madrid, Trotta, 2010, pág.I24.

${ }^{77}$ La Victimodogmática, analiza hasta qué punto y en qué medida el reconocimiento de la existencia en algunos supuestos delictivos, de víctimas que favorecen la consumación del hecho criminal, puede conducir a afirmar que éstas son corresponsables por haber contribuido a él con actos dolosos e imprudentes y en este sentido valorar una atenuación e incluso eximente de la responsabilidad del autor. AguiLAR AvilÉs, D. Estudios cubanos sobre victimología, Málaga, Grupo de Investigaciones EUMED, Universidad de Málaga, 2oro, pág. 35. Esa concepción remite a los primeros desarrollos de la Victimología centrados en el análisis del papel de la víctima en la consumación del delito. Otros autores plantean una visión más amplia de la Victimodogmática acorde con la propia evolución y transformaciones de la ciencia victimológica. Así para Landrove Díaz, la Victimodogmática haría referencia la influencia de la Victimología en el dogma jurídico-penal donde la estructura general del Derecho penal quedaría adaptada a las nuevas demandas sociales reivindicadas por la recogida legal de dicha disciplina. LANDROVE DíAZ ,G., La moderna victimología, Valencia, Tirant lo Blanch, I998.

${ }^{78}$ A este respecto y en el marco europeo, debemos recordar la aprobación el 25 de octubre de 2012 de la Directiva 20I2/29/UE del Parlamento Europeo y del Consejo de 25 de octubre de 2012 por la que se establecen normas mínimas sobre los derechos, el apoyo y la protección de las víctimas de delitos, y por la que se sustituye la Decisión marco 200I/220/JAI del Consejo (DOUE, $\mathrm{n}^{\circ}$ 3I5, I4 de noviembre de 20I2). El plazo general para que los Estados miembros adapten sus legislaciones al sentido de las disposiciones finaliza el i 6 de noviembre de 20I5. Su finalidad es garantizar que las víctimas de delitos reciban información, apoyo y protección adecuados y que puedan participar en los procesos penales (artículo I.I). El contenido de dicha norma se vertebrta en cinco derechos básicos: el derecho a la información, el derecho a la participación en el proceso, el derecho a la protección, el derecho a la asistencia y el derecho a la reparación. PÉREZ RIVAS, N., «Los derechos de las víctimas en la Unión Europea. Análisis de la Directiva 20I2/29/UE», Boletín CeDe UsC, febrero 2014 (disponible en

http://revistas.usc.es/boletincede/documentos/EditorialFebrerozoI4_Derechosvictimas_NataliaPerezRivas. pdf; fecha de consulta: I0.09.2014).
} 
autorizar a las víctimas a desconocer el Derecho penal como conjunto de garantías, significa más bien exigirle al Derecho penal que las tenga en cuenta para que el restablecimiento de sus derechos, su indemnización y reparación orienten al proceso penal» ${ }^{79}$.

En líneas generales el Derecho penal procura el castigo del culpable, en principio con una finalidad de reinserción social del mismo. De cara a las víctimas, busca el resarcimiento y el pago mediante la indemnización. Lo paradójico es que, para reparar el daño, este debe ser necesariamente medido, de otra forma no hay reparación posible. En determinados casos, como ocurre con las formas de victimización más grave, nos encontramos con una realidad insalvable en la inconmesurabilidad del dolor, a la que acompaña otra limitación radical: la irreparabilidad del sufrimiento.

Pero la conciencia de los límites del Derecho penal y sus funciones, no debe llevarnos a la conclusión errónea de que la cuantificación y la subsiguiente reparación del daño por ejemplo a través de la indemnización no sean relevantes en el proceso de desvictimización. Lo son y mucho. Sobre todo si tenemos en cuenta las consecuencias económicas que se derivan del delito, especialmente graves en el caso de las víctimas con escasos recursos. De hecho, y como no podía ser menos, dentro de este desarrollo de los derechos de las víctimas ocupa un lugar fundamental la mejora de los mecanismos de indemnización de las mismas. Es una de las maneras en las que el Derecho penal y la Administración de justicia, pueden mostrar su interés por las víctimas y su situación tras el delito. Pero también debemos ser conscientes de los propios límites del Derecho y de lo que razonablemente podemos esperar de él. Y asumir, en consecuencia, desde un enfoque victimológico amplio del sistema jurídico-penal, la necesidad de otros apoyos a la víctima más allá del campo, más bien limitado, de la justicia penal.

Pero prefiero dejar de momento aquí esta cuestión, para retomarla en el tercer bloque del análisis al hilo del supuesto concreto que presenta la película y de la reparación de las víctimas secundarias en caso de muerte de la víctima principal.

\section{IV.2. El deseo de venganza y el caballero}

En segundo lugar, analizaremos el deseo y la ejecución de la venganza por parte del caballero.

Para centrar el tema conviene que fijemos algunas consideraciones previas sobre el concepto de venganza. Por ejemplo, Frijda la define como «...el acto diseñado para dañar a alguien, o a algún grupo social en respuesta al sentimiento que uno mismo ha sido dañado por esa persona o grupo... el propósito inmediato de la revancha es, como establece la definición, hacer sufrir al [sujeto] objeto de venganza» ${ }^{80}$. Según Baum, las situaciones de inequidad, opresión y desigualdad social constituyen el marco propenso para despertar en los seres humanos emociones morales vindicativas. Sentirse vengativo, aunque no se lleve a

\footnotetext{
${ }^{79}$ Martínez, M., «Populismo punitivo mayorías y víctimas», Nomos-Universidad de viña del Mar, $\mathrm{n}^{\circ}$ 2, 2008, págs.I92.

80 El mismo autor esboza tres características del deseo de vengar: primero, se trata de una pasión autodestructiva y por lo tanto aparentemente inútil; segundo, posee tal intensidad, dada por la cantidad de veces que se le presenta a la víctima la profundidad de la ofensa y por el incremento de su fuerza impulsora, que es una de las emociones de mayor grado de violencia; y, tercero, es una emoción que persiste en el tiempo. FrIJDA, N. H., «Lex Talionis: On Vengeance», Van Goozen, S.M., van de Poll, N. van de Poll, N.E., Sergeant, J.A. (Ed.), Emotions: Essays on Emotion Theory, New Jersey, Lawrence Erlbaum Hillsdale,I994, pág. 265.
} 
cabo ningún plan dañino hacia otro ser humano, engendra en la sociedad vínculos jerárquicos. La persona que se sintió humillada, desposeída, lesionada, ultrajada o abandonada por la acción ofensiva del otro, se sintió menos que esa persona y busca (en justicia consigo misma) reparar su dolor y, al menos, volver a sentirse igual que el otro. Para ello, la persona ofensora deja de ser un igual para convertirse en un monstruo odioso, un demonio, que bajo los ojos de la herida pierde su humanidad ${ }^{81}$.

El tema de la venganza, encarnada en la figura de poder que es el personaje del señor feudal, pasa a ocupar un lugar central en la segunda parte de la cinta. Bergman muestra la importancia de esta cuestión en dos momentos clave: la preparación del caballero en una especie de rito de purificación y la ejecución del acto en otra escena brutal en la que los dos asaltantes (pero también el hermano menor inocente) son ejecutados. Partiremos aquí de una doble perspectiva: el análisis de la venganza a mano de las propias víctimas en el contexto jurídico social medieval y la pervivencia de ese sentimiento de las víctimas en la actualidad y como este es integrado o rechazado por las políticas criminales contemporáneas.

En el primero de esos momentos, y en una de sus escenas más terribles, la película se recrea en la preparación minuciosa del caballero para la venganza una vez que ha descubierto que los caminantes, a quienes inadvertidamente ha dado cobijo, son en realidad los asesinos de su hija. Espera paciente hasta el amanecer y, tras abatirlo como fue abatida la vida de su hija, corta con su propia espada algunas ramas de un arbol con las que azota su cuerpo desnudo mientras Ingeri vierte sobre él un barreño de agua caliente ${ }^{\delta_{2}}$. Es, por tanto, un rito de purificación cuasi religioso que muestra a las claras dos cosas: que la venganza no es en él un acto irreflexivo, en caliente, sino meditado y que constituye su derecho (e incluso su deber) como padre y señor ${ }^{8_{3}}$. Derecho que, como tal, conlleva un inherente grado de ritualización en su ejercicio. De hecho, al comienzo de ese segundo movimiento, justo antes de consumar la venganza, vemos al caballero aparecer en una especie de trono, revestido de todos los atributos de su poder feudal como recordando que estamos ante una prerrogativa de su elevada posición social.

Desde un punto de vista estrictamente histórico y atendiendo a la fecha de la balada origen de la historia, la película de Bergman se desarrolla en la baja edad media, época inserta todavía en lo que Schaffer denominó la edad de oro de las víctimas ${ }^{84}$. Esta fase se corresponde con el Derecho romano primitivo, el Derecho germánico y, en parte, con el

\footnotetext{
${ }^{81}$ BAUM, E., «Emociones, Justicia y Derechos Humanos», Revista Derecho y Ciencias Sociales, octubre $\mathrm{n}^{\circ}$, 20II, pág. 94.

${ }^{82}$ Como hacen notar Romasanta y Varela, el baño es el ritual purificador por excelencia en todas las culturas, ya que su simbolismo es muy transparente: el agua lava. También es simbólico el hecho de que para consumar la venganza el caballero solicite el cuchillo de sacrificar las reses, como si fuera un sacrificio oficiado al Dios vengador del Antiguo Testamento. Romasanta Iglesias, O., Calvo Varela, C. «Jungfrukällan: um conto maravilhoso», cit.,pág. 97.

${ }^{83}$ «Como todo en la vida de una sociedad primitiva, la venganza de sangre está permeada de religiosidad elemental. Esto garantiza que la vendetta o la Sippe se inserten en un ritual más o menos complejo. La función del ritual consiste en dar expresión a los sentimientos colectivos, y vehicular las acciones de los miembros del grupo. Es decir, la vendetta o la Sippe son sistemas rituales de regulación de la violencia. Se trata de una violencia hasta cierto punto definida y controlada. (...) Qué pariente deba vengar. Cuál deba ser el castigo o la compensación exigible, forman parte de las regulaciones rituales». PADIAL, J. J., «Venganza, realización de la libertad y guerra privada», Thémata. Revista de Filosofía, nº 48 julio-diciembre, 20I3, pág .91.

${ }^{84}$ SCHAFFER, S., The victim and his criminal: a study in functional responsibility, New York, Random House, I968.
} 
mismo Derecho medieval. En épocas más remotas, el ius puniendi se configuraba como un derecho privado de la víctima (o de su familia) que se alzaba como la protagonista absoluta del conflicto penal fijando la sanción y ejecutándola sobre la persona y los bienes del infractor $^{85}$. No obstante, pronto se pusieron de manifiesto los inconvenientes de este sistema (desproporción de la respuesta, posibles consecuencias en cadena que aumenten la conflictividad social) lo que hizo necesario la intervención de la comunidad como sujeto mediador del conflicto. Este es el sentido de leyes como la célebre Ley del Talión, reconocida en el Código de Hammurabi y en otros textos primitivos como la Ley de las XII Tablas.

Poco a poco, superando esa edad de oro de la víctima, se va dando paso pues a una idea evolucionada de venganza, en la que los intereses privados son sustituidos por los sociales. Se va configurando así la división de la tutela, según se trate de conflictos interpersonales con intereses privados, en los que las partes en el proceso eran las afectadas; y aquellos conflictos en los que los intereses sociales sustituían a los particulares $^{86}$. En el primer caso las partes eran las dueñas del proceso, mientras que en el segundo, las partes directamente afectadas no existían, y en su lugar se hallaba la sociedad y así despareció el propio concepto de conflicto o disputa, al producirse la expropiación del conflicto por parte del Estado ${ }^{87}$.

El moderno Derecho Penal entrañaba una concepción nueva del delito como atentado contra el orden social ${ }^{88}$, que se iba a diferenciar del daño causado a los perjudicados $^{89}$. En consecuencia el castigo abandonaría su inicial función reparadora e iría adquiriendo una función preventiva ${ }^{90}$. Con el advenimiento del Estado moderno ${ }^{9 \mathrm{r}}$ podemos hablar claramente ya de un monopolio de las instituciones del Estado en el ejercicio del ius puniendi. Tiene igualmente lugar la creciente diferenciación entre Derecho civil y Derecho penal como disciplinas que se ocupan, en este contexto, respectivamente de las relaciones

${ }^{85}$ SANZ-DiÉZ DE UlZURRUZ-Lluch, M., «La víctima ante el Derecho. La regulación jurídica de la víctima en el Derecho internacional, en el Derecho Europeo y en Derecho positivo español», Anuario de Derecho Penal $y$ Ciencias Penales, vol. LVII 2004, pág.220.

${ }^{86}$ BARONA Vilar, S., «Influencias de la Unión Europea e instancias supranacionales en la tutela penal de la víctima, en la Justicia Restaurativa y la Mediación Penal», Revista Judicial, Costa Rica, nº Io8 junio, 20I3, pág. 47.

${ }^{87}$ CHRISTIE, N., «Conflicts as Property», British Journal of Criminology, vol. I7, n I, I976, págs. I-I5.

${ }^{88}$ O como hizo notar Foucault directamente contra el propio soberano. «El delito, además de su víctima inmediata, ataca al soberano; lo ataca personalmente ya que la ley vale por la voluntad del soberano; lo ataca físicamente ya que la fuerza de la ley es la fuerza del príncipe». FouCAulT, M., Vigilar y castigar, Buenos Aires, S.XXI editores, 2002, pág. 45 .

${ }^{89}$ No obstante, como puntualiza Bazán, al menos en el contexto medieval hispánico, la implantación de la nueva filosofía penal, según la cual la pena era la consecuencia pública del delito, no supuso la erradicación absoluta de la venganza privada, aunque bien es verdad que quedó limitada a ciertos casos específicos. En especial, para aquellas acciones que suponían un atentado al honor familiar, como el rapto, la violación o el adulterio de mujer. BAZAN, I., «La pena de muerte en la Corona de Castilla en la Edad Media», Clio y Crimen, $\mathrm{n}^{\circ}$ 4, 2007 , pág. 310.

$9^{\circ}$ Roig Torres, M., «Algunos apuntes sobre la evolución histórica de la tutela de la víctima de delito», Estudios penales $\gamma$ criminológicos, $\mathrm{n}^{\circ} 22,2000$, pág. I64, págs. I53-308.

${ }^{91}$ De acuerdo con Padial, es propio de los ya nacidos y/o consolidados Estados nacionales «promulgar medidas encaminadas a acabar con la venganza, el duelo, la reyerta o la vendetta. Así en I48o los Reyes Católicos promulgaron la ley de Toledo, que amenazaba con la pena capital a quien se tomase la justicia por su mano y no recurriese a los tribunales de justicia ordinarios. Disposiciones legales semejantes tomaría en 1566 Carlos IX de Francia». PADIAL, J. J., «Venganza, realización de la libertad y guerra privada», cit., pág.86. 
entre delincuente y víctima (en lo relativo a la correspondiente pretensión indemnizatoria) y de la relación entre delincuente y Estado ${ }^{92}$.

En definitiva, a partir del S.XIII, se dibuja gradualmente el paso del proceso acusatorio al proceso inquisitorio. En este la víctima desaparece, como parte directamente interesada, tras el acusador público que impulsa la persecución del delito en nombre de la sociedad $^{93}$. Esto es, se va asistiendo paulatinamente a un proceso de neutralización de la víctima en el que el Derecho penal se convierte en un derecho público. Estado y delincuente pasan a ser los principales actores relegando a la víctima a un segundo plano ${ }^{94}$. Se observa como la regulación penal surge pues es su origen en el sentido de proteger a quien infringió la norma, es decir, al delincuente y no a la víctima, limitando así el ejercicio de la venganza privada

Pese a las evidentes ventajas que estas transformaciones implican en términos de pacificación social, acarrearon también una postergación de la víctima que pasó a ser contemplada como poco más que un simple testigo de cargo y, dado el caso como beneficiaria de una posible indemnización con no pocas dificultades. Esta situación, aunque con modulaciones y matices, se mantiene hasta el redescubrimiento de la víctima impulsado por el desarrollo de la Victimología que las llevará a recuperar parte de ese protagonismo perdido.

Volviendo al texto filmico aquí analizado, no tenemos muchos elementos para determinar con precisión el contexto jurídico-social en el que la venganza del caballero se produce. Su feudo parece poco importante y bastante aislado en el seno de una sociedad en la que el poder real se adivina distante y en el que incluso el cristianismo todavía convive con restos de paganismo vikingo. Bergman, en consonancia con el depurado estilo del film, no se detiene en explicaciones ni disquisiciones históricas sino que presenta de forma muy efectiva e impactante el acto de venganza en sus elementos más esenciales que también resuenan en nosotros como espectadores contemporáneos. No obstante, percibimos como incluso en términos medievales, la venganza del caballero, entendida como derecho y, en cierto sentido, también como obligación, tiene sus límites y sus reglas.

En la película esto se refleja en el destino del hermano pequeño de los asesinos, apenas un niño. Él fue un mero espectador del crimen en el que no intervino directamente, pero igualmente es asesinado por el caballero Torë lanzándolo brutalmente contra la pared. La madre de Karin trata incluso de protegerlo en un momento dado, y el propio caballero siente, en el fondo de su alma, como ha sobrepasado los límites racionales de la venganza contemplando el hecho de la muerte del niño, tan inocente como Karin, como un pecado al que le condujo la ira. Por ello, tanto el caballero como la madre tienen la conciencia de que la venganza que llevan a cabo, al incluir la muerte del niño hermano de los asesinos, excede su derecho y, en consecuencia, es contemplada, al menos parcialmente, como pecaminosa.

\footnotetext{
${ }^{92}$ Silva SÁnchez, J Ma , Perspectivas sobre la política criminal moderna, Buenos Aires, Ábaco, pág. I46.

${ }^{93}$ Peters, T., «Consideraciones teóricas sobre la victimología», Cuaderno Vasco de Criminología, nº 2, I988, pág.iıo.

${ }^{94}$ Silva SÁnchez, J Ma , Perspectivas sobre la política criminal moderna, cit., pág. I46.
} 
Es decir, según los mismos parámetros medievales, hay un aspecto legítimo en el ejercicio de la venganza privada ante el delito ${ }^{95}$ pero la configuración jurídico-social de la misma debería haber atendido a ciertos criterios de proporcionalidad. Puesto que, incluso en su concepción medieval, la venganza estaba limitada por el principio del talión, que suponía que no podía ir más allá del daño sufrido, y se encontraba moderada por la enmienda o la composición ${ }^{96}$.

Pero más allá de la reflexión basada en la literalidad del filme interesa aquí apuntar, siquiera sea a grandes rasgos, algunos elementos sobre la tensión entre el posible deseo de venganza de la víctima y los principios garantistas del Derecho penal.

Para empezar, deberíamos entender mejor las funciones de ese sentimiento de venganza en las víctimas insertas en el contexto de todo el proceso de victimización con sus múltiples consecuencias psicosociales. Para Fridja, ciertamente, la venganza «no restaura la pérdida o dolor que hay debajo del daño que he sufrido [como víctima], pero quita un poco de su ventaja o gloria; oculta mi vergüenza detrás de su vergüenza [del agresor] y mi dolor detrás del suyo» ${ }^{97}$. Desde el punto de vista estricto de la víctima el deseo de venganza sería, por lo tanto, un sentimiento con cierto grado de racionalidad funcional. Por ejemplo la ira hacia las personas que cometieron el crimen es una emoción que puede cumplir una primaria función autoprotectora en el duelo de los familiares ante muertes violentas como la que presenta la película ${ }^{98}$.

Y a la ira, aunque no necesariamente sea siempre así, le sigue el deseo de venganza sobre todo en la imagen o representación social construida de determinadas víctimas de delitos graves. Como señala Enrique Echeburúa, «la renuncia al deseo de venganza es una inevitable obligación social, pero la negación social de su necesidad psicológica puede convertirse en una segunda agresión. No hay víctima que no quede desgarrada por el conflicto entre la necesidad psicológica de la venganza directa y el imperativo social de resignarse a la justicia» ${ }^{99}$. Otra cosa es si esa emoción racional (hasta cierto punto) respecto de la víctima lo sigue siendo respecto de la sociedad en su conjunto y debe tener cobijo y apoyo por parte del sistema penal.

A partir de aquí surgen, por lo tanto, dos cuestiones importantes a determinar: la primera, si ese deseo de venganza que atribuimos a la mayoría de las víctimas está realmente tan extendido o tiene algo de proyección que sirve a los intereses políticos más punitivistas; la segunda, si el sistema jurídico-penal debe tener o no en cuenta de algún modo ese deseo de la víctimas o rechazarlo totalmente como irracional dentro de una concepción estrictamente garantista.

${ }^{95}$ En el contexto hispánico medieval de la Corona de Castilla, Iñaki Bazan, apunta entre los motivos por las cuales persistía la venganza privada frente al delito los pocos recursos del Estado para desempeñar la administración de justicia; el predominio del derecho consuetudinario; la existencia del derecho de solidaridad familiar, que suponía que el daño ocasionado a uno de sus miembros afectaba a todos por igual y, en consecuencia, el resarcimiento se alcanzaba a través de la venganza. BAZAN, I., «La pena de muerte en la Corona de Castilla en la Edad Media», cit., pág. 308.

${ }^{96}$ BAZAN, I., «La pena de muerte en la Corona de Castilla en la Edad Media», cit., pág. 308.

${ }^{97}$ FRIJDA, N. H., «Lex Talionis: On Vengeance», cit., pág. 282.

$9^{8}$ Corredor, A. M. «Estudio cualitativo del duelo traumático de familiares de víctimas de homicidio según la presencia o ausencia de castigo», Revista Colombiana de Psicología, nº II, 2002, pág. 37.

${ }^{99}$ ECheburÚA, E, «El valor psicológico del perdón en las víctimas y los ofensores», Eguzkilore, n²7. 20I3, pág. 7I. 
Respecto a la primera de las cuestiones, la misma Victimología como ciencia empírica tiene mucho que decir analizando a través de investigaciones lo que hay de verdadero y de construcción en el sesgo punitivista asociado al deseo de venganza que se suele atribuir a las víctimas. Lo cierto es que no son pocos los trabajos que ponen en cuestión estas concepciones $^{\text {100 }}$. Para Larrauri, «la demanda de penas más severas se produce generalmente por gente que no ha sido directamente victimizada. La propia víctima en ocasiones quiere renunciar a la pena a cambio de una reparación, pero es precisamente el Estado y la concepción de la pena pública la que fuerza su imposición ${ }^{\text {ror }}$.

Ese punitivismo que saciaría el deseo de venganza, real o proyectado, de las víctimas puede ser fácilmente manipulado y convertido, como de hecho así ha sido en buena parte de los sistemas criminales contemporáneos, en una de las bases del populismo penal ${ }^{102}$ justificando las políticas de mano dura y agravamiento de las penas en algunos delitos. Porque, como hace notar Bernardo del Rosal, todo ello se integra en una importante transformación de los sistemas penales que ha venido concretándose en las últimas décadas que implica que éstos «no sólo castigan más con penas de prisión que cada vez más largas en su duración, es que lo hacen, primero, en un contexto de evolución interrumpida hacia la racionalidad y la humanización, que orientaba hacia un uso más moderado y restringido de la prisión, y, segundo, lo hacen reduciendo los fines de la pena a la inocuización, convirtiendo al riesgo en referente esencial de la intervención penal, aplicando técnicas actuariales de control del riesgo, haciendo uso del populismo penal, convirtiendo a la víctima en un icono e implicando de forma diferente a la sociedad en el diseño y ejecución de las políticas penales, haciendo renacer sanciones que se consideraban obsoletas e impropias de sistemas penales avanzados ${ }^{\text {103 }}$.

Como vemos, un elemento importante dentro de estas transformaciones es el haber convertido a la víctima en un icono. Para Simon, la víctima de delito, o al menos cierto tipo de víctimas (porque no hay que olvidar el proceso social de selección y jerarquización de las mismas), se contempla como un ciudadano/a idealizado/a. Un ciudadano cuyas demandas más o menos coinciden con aquello que el propio Estado sabe hacer con mayor efectividad: utilizar su poder para castigar ${ }^{\text {ro4. }}$. De esta forma, cuando las víctimas se vuelven un elemento esencial en el clamor de medidas cada vez más punitivas abanderan aparentemente con su

\footnotetext{
${ }^{100}$ Sería muy prolijo enumerar aquí toda la literatura sobre este tema. Pero, por ejemplo, así lo resaltan, entre otros, destacados autores como Sessar, K., Beurskens, A., Boers, K., «Wiedergutmachung als Konfliktregelungsparadigma?», Kriminologisches Journal, vol.ı8, n 2, I986, págs. 86-IO4; JoHNSTONE, G., «Penal Policy Making: Elitist, Populist or Participatory?», Punishment \& Society, n² 2, 2000, págs. I6I-I80.

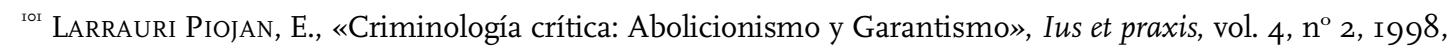
pág. 42.

${ }^{102}$ La literatura sobre este fenómeno el populismo penal es muy abundante e imposible de reseñar en este espacio. Nos limitaremos a recoger una definición de populismo penal de Bernardo del Rosal que sintetiza la aportación de muchos autores y que lo configura como «el fenómeno consistente en tomar las decisiones de la política criminal sobre la base de las demandas que nacen de la experiencia cotidiana, de las percepciones y de los sentimientos del pueblo, haciendo, entonces, que esas opiniones, o, si se prefiere, que esa opinión pública, sea la fuente del nuevo conocimiento penal y de la ley penal, sin que puedan intermediar reflexivamente, entre esas demandas (fruto de esos sentimientos y emociones) y las decisiones políticas, los expertos, cuyas opiniones, además, parecen estar ahora desacreditadas». DEL RosAL, B., «¿Hacia el Derecho penal de la postmodernidad?», Revista Electrónica de Ciencia Penal y Criminología, n II, 2009, pág. 46 (disponible en:

http://criminet.ugr.es/recpc/ıI/recpciı-08.pdf; fecha de consulta: I0.09.20I4).

${ }^{\text {I03 }}$ DEL RosAL, B., «نHacia el Derecho penal de la postmodernidad?»,cit., p.I9.

${ }^{104}$ Simon, J., Governing through Crime: How the War on Crime Transformed American Democracy and Created a Culture of Fear, Oxford, Oxford University Press, 2007, pág. 136.
} 
sentido de la autenticidad y su valor moral un tratamiento que, de otra forma, sería visto como meramente vengativo. Estas llamadas a condenar más y a entender menos las causas del crimen resultan más persuasivas si se subrayan con los testimonios y las historias de las propias víctimas ${ }^{\text {105. }}$. En este sentido, es muy relevante el papel de la opinión pública y de su construcción a través de los medios de comunicación social en su tratamiento periodístico del delito. Especialmente de algunas formas de delito semejantes al presentado en la película de Bergman ${ }^{\mathrm{ro6}}$.

En definitiva, y esta sería la conclusión que responde a la segunda de las cuestiones que planteábamos más arriba, como bien advierte Mauricio Martínez «el Derecho penal no puede representar la prolongación de la venganza, sino como sistema de garantías, para arrebatar al incriminado de las manos del sistema punitivo ilimitado y de las víctimas y de las mayorías que en su irreparable dolor o instrumentalizadas por oscuras campañas, pueden ser más ofensivas y catastróficas que el delito mismo». ${ }^{107}$ Esta es una reflexión muy pertinente para el futuro de la Victimología como disciplina científica rigurosa y no como mero programa de activismo social no académico. Una advertencia para evitar que, con la excusa de una mejor atención de los intereses de las víctimas, se acabe convirtiendo en una coartada revestida de ciencia para políticas de endurecimiento de las políticas criminales como muchos críticos le han recriminado.

Desde una postura garantista, cobra sentido la búsqueda de un equilibrio entre la tradicional neutralización de la víctima que implica el carácter público del ius puniendi y la atención adecuada a sus necesidades por parte del sistema jurídico y la Administración de justicia y el conjunto de los poderes públicos.

Esto no implica, desde luego, que no se emprendan transformaciones que supongan una participación más activa de la víctima en el proceso por ejemplo, en algunos casos al menos, a través del modelo de justicia restaurativa ${ }^{\mathrm{a} 8}$. Este modelo de justicia parecería conectar mucho más eficazmente con esa preocupación y atención a las víctimas que ha favorecido la Victimología sobre todo desde sus sesgos más activistas al centrarse

${ }^{105}$ Mc Evoy, K. McConnachie, K., «Victimology in transitional justice: Victimhood, innocence and hierarchy», European Journal of Criminology, 9 (2), 2012, pág. 530.

${ }^{106}$ Como apunta críticamente Fuentes Osorio, a pesar de que el tratamiento de los medios de comunicación respecto del crimen tiene aspectos positivos, como el presentar un problema social, los límites de este y favorecer el debate público sobre el mismo, estos, en su opinión suelen presentar «una realidad criminal distorsionada. Se sobredimensiona la gravedad y la frecuencia de ciertos acontecimientos al tiempo que otros hechos delictivos cotidianos son condenados al ámbito de lo excepcional. (...) De este modo contribuyen a la aparición y al refuerzo de errores cognitivos en el auditorio (p.e. respecto a la probabilidad de ser víctima del delito). [Estas representaciones distorsionadas] son factores de presión sobre los agentes políticos, que se ven obligados a reaccionar de forma inmediata y contundente con una ley penal. Y así manifiestan su intención de no hacer concesiones, su capacidad de actuación, su celeridad a la hora de enfrentarse a los problemas. (...): crean una imagen que evita discusiones sobre problemas estructurales de difícil solución, crean una imagen que se puede esgrimir en los medios contra el contendiente político». FUENTES Osorio, J.L., «Los medios de comunicación y el Derecho Penal», Revista Electrónica de Ciencia Penal y Criminología, n 7, 2005, págs.3-4 (disponible en http://criminet.ugr.es/recpc; fecha de consulta: 08.09.20I4).

${ }^{107}$ MARTíneZ, M., «Populismo punitivo mayorías y víctimas», cit., pág.I92.

${ }^{108}$ Arrona define la justicia restaurativa como «un nuevo modelo de justicia en el que las personas afectadas directamente por un delito o infracción (víctima, agresor y comunidad) logran mediante un proceso de carácter no punitivo, reparativo y deliberativo, alcanzar la solución del conflicto y la restauración de las relaciones sociales quebrantadas por la comisión del hecho ilícito de una forma distinta que la que ofrece el sistema penal tradicional; tomando en cuenta las condiciones tanto de la víctima como del agresor». ARRonA PALACIOS, A., «La influencia de la Victimología en la justicia restaurativa y los programas de mediación», Quadernos de criminología, $\mathrm{n}^{\circ}$ I6, 2012, págs.6-II. 
mucho más en la reparación de su sufrimiento y ponderar mejor todas sus circunstancias que la justicia retributiva tradicional. Las víctimas recuperarían así el conflicto que la Administración de justicia les había expropiado pero no para solucionarlo con la venganza sino a través del diálogo y el acuerdo sobre la reparación. Para Arturo Arrona, la justicia restaurativa termina suponiendo «una visión de la justicia desde y hacia las víctimas, es decir, justicia que se debe a las víctimas y justicia que emana de las víctimas; teniendo todo un trasfondo victimológico para la ayuda y el cuidado de la víctima ${ }^{\text {109 }}$.

En definitiva, reparar a las víctimas, desde un concepto victimológico amplio sería mucho más que atender a su supuesta sed de venganza vehiculada a través de la justicia criminal entendida solo desde un punto de vista retributivo. Con todo creo que hay que evitar pensar en la justicia restaurativa como una especie de panacea universal para las víctimas; debemos elaborar programas rigurosos en este sentido y seguir reflexionando críticamente sobre la adecuación o no de este tipo de soluciones en determinados tipos de delitos $^{\text {IIO }}$.

\section{IV.3. El sentimiento de pérdida, el duelo y los familiares}

La tercera y última parte de nuestro análisis se centra en los familiares, sobre todo los padres que sobreviven, así como en el sentimiento de pérdida de esas víctimas secundarias especialmente en delitos que, como en el caso del film, implican la muerte de un familiar o de alguien próximo. Nos ocuparemos del trauma y del duelo complicado que pueden estar asociados a estas situaciones.

La película presenta, como hemos visto, varios tipos de víctimas: la doncella como víctima directa pero también los padres y otras personas cercanas como víctimas indirectas. E incluso deberíamos añadir como víctima al hermano inocente ajusticiado por el caballero. Dedicaremos la última parte de nuestro análisis en las víctimas indirectas, sobre todo encarnadas en la figura de los padres.

En la actualidad, tanto en las clasificaciones teóricas victimológicas como en los documentos jurídicos esenciales en el desarrollo de los derechos de las víctimas, son consideradas como tales, al menos en determinados supuestos, los familiares y las personas cercanas de las víctimas directas. Así se desprende, por ejemplo, de la Declaración de la ONU de 1985 sobre los principios fundamentales de justicia para las víctimas de delitos y del abuso de poder ${ }^{\text {III }} \mathrm{y}$, en el contexto europeo, de la reciente Directiva 2012/29 de 25 de octubre $^{\mathrm{II} 2}$.

${ }^{109}$ Arrona Palacios, A., «La influencia de la victimología en la justicia restaurativa y los programas de mediación», cit., pág.II.

${ }^{\text {ro }}$ Un ejemplo de ello sería la discusión presente en la literatura científica internacional sobre la utilidad y viabilidad de este tipo de programas restaurativos en casos de violencia familiar y de género. Para un acercamiento inicial puede consultarse un buen resumen de los argumentos en contra y a favor en: STRUBв, J., «Restorative Justice, Domestic Violence and Family Violence», Australian Domestic and Family Violence Clearinghouse, Issues, paper 9, 2004, págs. I-23.

${ }^{\text {II }}$ Que en el párrafo 3 señala que en la expresión víctima «se incluye además, en su caso, a los familiares o personas a cargo que tengan una relación inmediata con la víctima (...)». Declaración sobre los Principios Fundamentales de Justicia para las Víctimas de Delito y del Abuso de Poder, ARES/40/34 Resolución de la Asamblea General de Naciones Unidas, ANEXO, 1985.

${ }^{\text {II2 }}$ En este texto en la definición de víctima se incluyen expresamente a «los familiares de una persona cuya muerte haya sido directamente causada por un delito y que haya sufrido un daño o perjuicio como consecuencia 
De una forma genérica ya hemos abordado las consecuencias psicológicas del delito en las víctimas, del posible trauma, y del proceso de desvictimización. Pero me gustaría detenerme ahora en algunas consideraciones específicas sobre el trauma y el duelo en los familiares y otras personas cercanas de víctimas mortales de delitos violentos, y la subsiguiente intervención que puede requerirse. Desde una perspectiva psicopatológica, un suceso traumático genera síntomas ansioso-depresivos y conforma una profunda transformación de la visión de la vida y de los valores más íntimos. En cambio, el duelo supone, en general, una reacción adaptativa ante la muerte de un ser querido, que obliga al sujeto afectado a plantearse su propia muerte y a rehacer su vida desde una perspectiva distinta ${ }^{\mathrm{II}}$.

Como recuerda Pérez Trenado, la pérdida de un ser querido puede ser el factor más estresante en la vida de una persona, especialmente si se produce de forma imprevista y se trata de un hijo o hija. El proceso de aceptación de su muerte es el más difícil de todos. En definitiva, por sí misma, la muerte de un hijo es un hecho antinatural, que produce una inversión del ciclo biológico normal ${ }^{114}$. Pero además, las muertes violentas, ya sean por asesinato o por suicidio, constituyen un apartado especial en la recuperación de los supervivientes ${ }^{\mathrm{II}}$.

En caso de muerte de un familiar o persona cercana, el duelo constituye una experiencia cultural universal, subjetiva, que va a requerir una elaboración posterior, cuya duración va a depender de la persona, pero que se ve influido por varios factores ${ }^{\mathrm{ri}}$. En supuesto de la muerte violenta de un hijo o hija, el hecho traumático se funde con el duelo ${ }^{\text {II7 }}$.

Con frecuencia, el hecho de que la pérdida se haya producido en estos casos por una muerte violenta puede llevar por lo tanto a un duelo difícil de superar que persista más allá

de la muerte de dicha persona» (art.I. a. ii) pero se considera simplemente como familiares al «cónyuge, la persona que convive con la víctima y mantiene con ella una relación personal íntima y comprometida, en un hogar común y de manera estable y continua, los familiares en línea directa, los hermanos y hermanas, y las personas a cargo de la víctima» (art I.b) Al tiempo que en el art.2 establece que los «Estados miembros podrán establecer procedimientos: a) para limitar el número de familiares que puedan acogerse a los derechos establecidos en la presente Directiva, teniendo en cuenta las circunstancias específicas de cada caso, y b) por lo que respecta al apartado I, letra a), inciso ii), para determinar qué familiares tienen prioridad en relación con el ejercicio de los derechos establecidos en la presente Directiva».

${ }^{\text {inz }}$ Pérez Cuesta, M., Nicuesa, M.J., «Afrontar el proceso de duelo», Astudillo,W., García de Acilu,A., Mendinueta C., ARrietA, C., (eds.), Estrategias para la atención integral en la terminalidad, Bilbao, Sociedad Vasca de Cuidados Paliativos, I999.

${ }^{114} \mathrm{Ni}$ siquiera hay un término para describir al superviviente, como lo hay en el caso de la pérdida de un padre (huérfano) o de un marido (viuda). Según este mismo autor, alrededor de un $20 \%$ de los padres que pierden a un hijo no llegan a superarlo nunca. PÉREZ TRENADO, M., «El proceso de duelo y la familia», Astudillo, W., Arrieta,C., Mendinueta, C., Vega de Seoane, I., (eds.), La familia en la terminalidad, Bilbao, Sociedad Vasca de Cuidados Paliativos, I999.

${ }^{\text {II5 }}$ ECheburúA, E., Superar un trauma: el tratamiento de las víctimas de sucesos violentos. Madrid. Pirámide, 2004, pág.39.

${ }^{116}$ AcinAs, P., «Duelo en situaciones especiales: suicidio, desaparecidos, muerte traumática», $\mathrm{n}^{\circ}$ I Revista Digital de Medicina Psicosomática y Psicoterapia, $\mathrm{n}^{\circ}$ I, vol. 2, 20I2, pág. 2 (disponible en:

http://www.psicociencias.com/revista/boletines/Duelo\%2oen\%2osituaciones\%2oespeciales.pdf; fecha de consulta: I0.09.2014).

${ }^{\text {r77 }}$ Echeburúa define el duelo como «el conjunto de reacciones de tipo físico, emocional y social que se producen por el fallecimiento de una persona próxima y que pueden oscilar desde un sentimiento transitorio de tristeza hasta una desolación completa, que, en los casos más graves, puede durar años e incluso toda la vida». EChebURÚA, E., Superar un trauma: el tratamiento de las víctimas de sucesos violentos, cit., págs. 340-34I. 
de lo razonable, esto es, a un duelo complicado ${ }^{\text {r18 }}$. Para Worten, este tipo de muertes tienen un serie de características que hacen mucho más difícil de elaborar el duelo subsecuente: dejan al superviviente con la sensación de irrealidad e incredulidad, de que la pérdida no es real; se produce una exacerbación de los sentimientos de culpa, necesidad de culpar a alguien, sensación de impotencia en el superviviente que presenta una agitación manifiesta, sensación de lucha- huida; los asuntos no resueltos son para los supervivientes una fuente de preocupación importante, porque generan remordimientos; hay un aumento de la necesidad de entender lo sucedido y porqué una persona puede morir en esas circunstancias de una manera totalmente inesperada; finalmente, algunos sobrevivientes pueden sentirse victimizados por el sistema ${ }^{\text {II9 }}$.

La intervención ante estos tipos de duelo sigue una secuencia peculiar. Según Echeburúa, un primer paso es aceptar la realidad de la pérdida. La experiencia compartida del dolor y de la pena es un segundo paso para la superación del duelo. Un tercer paso es proceder a la reorganización del sistema familiar asumiendo las funciones del rol del difunto. Y un cuarto paso es establecer nuevas relaciones y metas en la vida, lo cual no es siempre fácil por el sentimiento de lealtad al fallecido y por el temor a nuevas pérdidas ${ }^{\mathrm{I20}}$.

Hasta ahora nos hemos referido al acompañamiento psicosocial en el proceso de desvictimización, que como sabemos es multidisciplinar y abarca diferentes actuaciones desde diversos ámbitos. Pero ¿cuál sería el papel del sistema jurídico-penal en estas situaciones? Nos interesan sobre todo dos cuestiones: de un lado cómo afecta la intervención de la justicia penal a los procesos de duelo de los familiares; de otro lado, retomaremos la cuestión que apuntábamos más arriba respecto la indemnización, pero centrándonos en el caso concreto de los familiares de víctimas mortales de delitos violentos.

En relación con el papel del sistema jurídico, como veíamos, Worten incluye el hecho de que los familiares supervivientes se puedan sentir victimizados como una de las características que dificultan la elaboración del duelo en este tipo de muertes violentas. Es decir, los familiares de la víctima, como víctimas indirectas, pueden ser objeto de victimización secundaria por parte del sistema jurídico penal de muy diversas maneras: si nos centramos solo en el ámbito judicial, desde la incertidumbre de un proceso penal que parece no acabar, el revivir en el juicio oral (celebrado generalmente mucho después del delito) todos los hechos hasta que se pueda poner en duda el propio comportamiento que tuvo la víctima. Los jueces se limitan a aplicar el ordenamiento jurídico que no está pensado para proteger a las víctimas sino para perseguir a los culpables ${ }^{\mathrm{r21}}$.

En ese contexto, para Corredor, el castigo para los homicidas desde el punto de vista del duelo traumático cumpliría una doble función en los dolientes: sirve para realizar la

\footnotetext{
${ }^{\text {rI8 }}$ De acuerdo con Ana María Corredor, «El duelo de los allegados a las víctimas de homicidio suele pensarse como duelo complicado o, recientemente, como conjunción de las características del duelo normal y trauma». Los duelos complicados son aquellos en los que no se alcanza la acomodación y se caracterizan por intensidades y/o duraciones exageradas o demasiado leves de las reacciones del duelo más que por la presencia o ausencia de algunos síntomas determinados. CoRREDOR, A. M., «Estudio cualitativo del duelo traumático de familiares de víctimas de homicidio según la presencia o ausencia de castigo», cit., pág.36.

${ }^{\text {Irg }}$ Worden, J.W., El tratamiento del duelo: asesoramiento y terapia, Barcelona, Paidós, 2002.

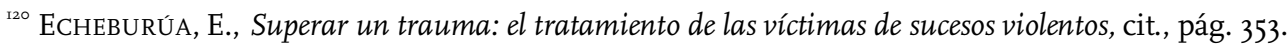

${ }^{\text {I2r }}$ Echeburúa, E. De Corral, P. Amor, P.J. «Evaluación del daño psicológico en víctimas de delitos violentos», Psicothema, vol. I4, 2002, pág.I42.
} 
tendencia a la acción de la irá y así permite el manejo de la emoción. También puede restaurar la noción de justicia y equidad devolviéndoles la fe general en el mundo y en las personas (si la tuvieron antes del homicidio) ${ }^{122}$. En cualquier caso dependerá de cada persona y no está claro que el castigo tenga estos efectos en las víctimas en todos los $\operatorname{casos}^{123}$. A este respecto Robert Elias se pregunta « ¿Cómo podemos esperar que las víctimas no crean que lo que necesitan es venganza cuando el derecho, la ideología y el movimiento a favor de las victimas dominante les han dicho repetidamente que lo que necesitan es que se castigue duramente a los agresores: para calmar su rabia y para autoprotegerse? En nuestra cultura de soluciones violentas no hemos ofrecido otra alternativa a las víctimas que no sea la venganza ${ }^{\mathrm{I} 24}$. No obstante el mismo autor hace notar cómo a pesar de esas presiones la mayoría de las víctimas no busca venganza y, como ya veíamos y evidencian numerosos estudios, las víctimas resultan bastante menos punitivistas de lo que se podría pensar ${ }^{125}$.

En relación con la indemnización, en el caso de los delitos más graves, como ya hemos apuntado más arriba, nos encontramos con dos características del daño que muestran claramente las limitaciones de la intervención del Derecho: la inconmensurabilidad del dolor y la irreparabilidad de determinados sufrimientos ${ }^{\mathrm{I} 26}$. Desde luego, esto no significa que la indemnización no sea una cuestión importante para las víctimas dentro de lo que el derecho puede aportar a las mismas. Hay aquí un cierto paralelismo con lo que ocurre con la medicina que aunque mejora nuestra calidad y expectativas de vida también tiene sus límites y nada o muy poco puede hacer frente a algunas enfermedades. Lo cierto es que la indemnización judicial a partir de la responsabilidad civil asociada al delito siempre parecerá poca cosa y totalmente insuficiente si no se acompaña de otros tipos de apoyo como parte del resarcimiento de la víctima ${ }^{\text {I27 }}$. Sobre todo ante la magnitud de determinados daños como la muerte de una hija o hijo asesinado brutalmente.

Esto se percibe mejor si partimos del tratamiento concreto de la cuantificación de la indemnización a la víctima de un delito similar al que se produce en la película por ejemplo en el ordenamiento jurídico español ${ }^{128}$.

\footnotetext{
${ }^{122}$ En este sentido, «la lógica del castigo para las personas difiere de la lógica del proceso penal y por eso los dolientes pueden frustrarse aunque conozcan los procedimientos y, en términos legales los procesos marchen con corrección» CORREDOR, A. M., «Estudio cualitativo del duelo traumático de familiares de víctimas de homicidio según la presencia o ausencia de castigo», cit., págs. 53-54.

${ }^{123}$ No está de más recordar aquí las palabras de Nino: «Muchos no vemos claro cómo la suma de un mal más otro mal puede dar como resultado, no dos males, sino un bien. Tampoco percibimos nítidamente una diferencia sustancial entre la pena retributiva y un hipotético sistema de venganza en gran escala organizado en forma monopólica por el Estado (quizás...la venganza no es tan mala cuando se lleva a cabo en forma prudente y organizada)» Nino, C. S., Ética y Derechos Humanos. Un ensayo de fundamentación, Buenos Aires, Astrea y Depalma, 2 edición, 2007, págs. 448-45I.

${ }^{124}$ ELIAS, R., «Paradigms and Paradoxes of Victimology, International Victimology», cit., pág. 2I.

${ }^{125}$ ELIAS, R., «Paradigms and Paradoxes of Victimology, International Victimology», cit., pág. 22.

${ }^{126}$ MADRID, A., La política y la justicia del sufrimiento, cit., p.I24.

${ }^{127}$ A esto hay que añadir que es relativamente frecuente que se frustren las expectativas de obtener un resarcimiento del daño sufrido en el delito aunque se obtenga una sentencia condenatoria porque el condenado muchas veces es insolvente y los mecanismos de que dispone el Estado para atender a la reparación de la víctima, aunque van mejorando, son limitados. Silva SÁnCHEZ, J.Mª., Perspectivas sobre la política criminal moderna, Buenos Aires, Ábaco, pág. I46.

${ }^{128}$ En la Directiva 20I2/29 UE el derecho a reparación recibe una regulación fragmentaria, limitándose el texto a señalar que los Estados garantizarán la obtención, por la víctima, de una reparación pecuniaria a cargo
} 
En el caso de muertes, como algún sistema hay que aplicar para dicha valoración, se introdujo en España un sistema para la valoración de los daños y perjuicios causados a las personas derivados de un accidente de circulación. Este sistema, también llamado baremo que se aplica para valorar las lesiones sufridas por las personas en el ámbito de la circulación de vehículos a motor y que resulta vinculante en este terreno ${ }^{\mathrm{I} 2}$, se utiliza en la práctica como referencia para cuantificar las indemnizaciones derivadas de otros delitos, aunque sin carácter vinculante, por las ventajas que ofrece (certeza y seguridad jurídica, trato análogo en casos semejantes, impulso para alcanzar acuerdos transaccionales). En lo que se refiere a las indemnizaciones por muerte, la cuantía de la reparación se fija mediante la conjunción de la línea correspondiente a los perjudicados/beneficiados de la indemnización con la edad de la víctima ${ }^{\mathrm{I30}}$. Las cuantías, teniendo en cuenta la enorme dificultad de valoración del daño por el que se indemniza, tienden a parecer casi siempre sobre todo ante determinadas situaciones graves como escasas ${ }^{131}$.

A ello habría que añadir que, aunque solo en caso de insolvencia o insolvencia parcial del condenado y no existiendo un seguro privado, los padres de una víctima mortal de delito podrían beneficiarse de las prestaciones recogidas en la Ley 35/1995 de 11 de Diciembre de ayudas y asistencia a las víctimas de delitos violentos y contra la libertad sexual (BOE, $\mathrm{n}^{\circ}$. I26, 27 de mayo de 1997) que recoge esta posibilidad en determinadas circunstancias ${ }^{132}$.

En definitiva, por trasladar el caso de la película a esta discusión, ¿cómo podemos realmente resarcir a unos padres económicamente de la muerte brutal de su hija? Lo cierto es que, como concluye Antonio Madrid, el derecho que se había propuesto domesticar el

del infractor en el marco del proceso y en un plazo razonable (artículo i6). PÉREZ RivAs, N., «Los derechos de las víctimas en la Unión Europea. Análisis de la Directiva 20I2/29/UE», cit., pág. 9.

${ }^{129}$ Real Decreto Legislativo 8/2004, de 29 de octubre por el que se aprueba el Texto refundido de la Ley sobre Responsabilidad Civil y Seguro en la Circulación de Vehículos a Motor (BOE $\mathrm{n}^{\circ} .267$, de 5 de noviembre de 2004).

${ }^{130}$ Comprende la cuantificación de una indemnización básica integrada por unos daños morales idénticos y un lucro cesante básico, que tiene en cuenta básicamente: el número de perjudicados y su relación con la víctima y la edad de la víctima (referida a la fecha del accidente). A ello se añade el importe de los gastos correspondientes a asistencia médica, farmacéutica y hospitalaria, y los de entierro y funeral. Por último, en concepto de factores de corrección, se añade un porcentaje conforme a una escala de ingresos netos por trabajo personal, incluyéndose cualquier víctima en edad laboral, aunque no se justifiquen ingresos hasta un importe, dos tramos, y un cuarto a partir de otro importe. Como circunstancias familiares especiales, la discapacidad física o psíquica acusada, anterior al accidente, del perjudicado o beneficiario, que se conecta, por tramos, con la naturaleza de la víctima por relación con aquél, y su edad; así como la víctima hijo único, según su edad. OcHOA CAteleiro, A., «La indemnización de la víctima en el proceso penal español y la nueva directiva de la UE», Good Practics for protecting victims, 2013, pág 7. (disponible en:

http://www.protectingvictims.eu/upload/pages/65/Indemnizacion.it.en.pdf; fecha de consulta: I0.09.20I4).

${ }^{131}$ En España, según la actualización del último baremo de marzo de 20I4, para un caso cómo el de la película, si se aplicara este sistema, se reconocería a los padres una indemnización básica de I05.448,93 euros, que incluye no olvidemos los daños morales (tabla I) aunque esta podría ser aumentada a 1 tratarse de una hija única menor de un 30 a un 50\% (Tabla II). Resolución de 5 de marzo de 2014, de la Dirección General de Seguros y Fondos de Pensiones, por la que se publican las cuantías de las indemnizaciones por muerte, lesiones permanentes e incapacidad temporal que resultarán de aplicar durante 2014 el sistema para valoración de los daños y perjuicios causados a las personas en accidentes de circulación.

${ }^{132}$ En cualquier caso la víctima debería ser menor (art. 2.5) o los padres depender económicamente de esta y no existir cónyuge o hijos dependientes de la víctima (art. 2.Ic). Como señala Caravaca Llamas, en la mayoría de los casos, estas prestaciones no se corresponden con lo que a las víctimas les correspondería percibir en las indemnizaciones fijadas, ya que son cuotas temporalmente limitadas y cuyo importe varía según la casuística recogida reglamentariamente. CARAVACA Llamas, C., «Política Social y asistencia a las víctimas de delitos en España: del reconocimiento legal a la protección social», cit., pág. 8. 
sufrimiento no puede hacerlo del todo mediante esta operación. Al menos en los casos más graves, no es posible para el Derecho reparar lo irreparable. Choca, por lo tanto, con la dimensión trágica de determinados sufrimientos ${ }^{133}$.

Finalmente, otro elemento interesante que sugiere la película relacionado con estas cuestiones es la de la memoria y el recuerdo de las víctimas. En las últimas escenas, los familiares y personas cercanas a la doncella, encabezados por los padres, a recoger el cadáver de su hija. Este final de la película remite también a la importancia cultural de honrar a los muertos con un entierro digno y, al menos en culturas como la nuestra, de tener un lugar físico al que acudir y en el que rendir memoria y tal vez aplacar así el dolor de la traumática pérdida ${ }^{\mathrm{I} 4}$. Como señala Patrícia Acinas, «hasta que no hay constancia real de que el cuerpo ha aparecido sin vida, no hay un permiso personal y social para empezar a elaborar el duelo; el cuerpo sin vida es el elemento que confirma fehacientemente la muerte irreversible» ${ }^{135}$. El encontrar el cadáver y darle sepultura digna puede ser el principio de una mejora en la situación emocional de las víctimas ${ }^{136}$. En el caso de la película el caballero, arrodillado ante Dios a pesar de que siente que le abandonado, promete levantar en aquel mismo lugar un recuerdo perdurable en memoria de su hija: una iglesia, pero no de madera como solían serlo algunas primitivas iglesias escandinavas medievales, sino de piedra y cal.

La obligación ética del recuerdo de las víctimas, que se reivindica en la justicia anamnética, afecta a la misma percepción de la realidad: «De la realidad que queda o sobrevive al asesinato forma parte una ausencia que afecta la presencia de dos formas: negativamente, como una herida que sufre la parte superviviente, y positivamente, como una mirada específica que forma parte de la realidad, de tal manera que si no se tiene en cuenta no podemos conocer la realidad en su totalidad $»^{\mathrm{r}}{ }^{37}$. De hecho hemos visto como el acompañamiento del duelo tiene como una de sus finalidades colocar de nuevo a la víctima en la realidad de la pérdida.

No hay justicia sin memoria pero la gestión del recuerdo tiene que ir unida a cierta práctica del olvido porque de otra forma no podríamos vivir. El olvido, al menos en cierto grado posible, es terapéutico y por eso, en casos similares la historia de la doncella, la atención y el apoyo de las víctimas, sobre todo en su vertiente psicológica, se dirige prioritariamente hacia la recuperación a partir del tratamiento y la superación del trauma, a

\footnotetext{
${ }^{133}$ MADRID, A., La política y la justicia del sufrimiento, cit., p.I24.

${ }^{134}$ Como señala Susan Sontag, «El recuerdo es, dolorosamente, la única relación que podemos tener con los muertos. Por tanto, la creencia de que recordar es un acto ético se encuentra muy adentro de nuestra naturaleza como humanos, que sabemos que moriremos, y que lloramos a los que en el curso normal de las cosas mueren antes que nosotros: abuelos, padres, maestros y amigos mayores. Crueldad y amnesia parecen ir juntos» Ese recuerdo es especialmente doloroso y traumático y la necesidad ética de recordar parece más acuciante cuando la pérdida no proviene del curso normal de las cosas sino de un acto de brutal violencia. SonTAG, S., Ante el dolor de
} los demás, Barcelona, Random House, 2003, pág.iıo.

${ }^{135}$ ACINAS, P., «Duelo en situaciones especiales: suicidio, desaparecidos, muerte traumática», cit., pág.I2.

${ }^{136}$ Piénsese por ejemplo en el caso, por cierto no tan alejado del presentado por la película, de Marta del Castillo y cómo se destaca constantemente en el tratamiento mediático del mismo el hecho de que no se haya encontrado su cadáver incrementa el dolor de los padres. La supuesta falta de colaboración de la persona condenada por este crimen a la hora de facilitar información fidedigna a las autoridades sobre el lugar al que arrojó el cadáver sirve para sustentar el relato y la imagen mediática del monstruo.

${ }^{137}$ Torralba, F., Palazzi, C., «El deber de recordar a las víctimas: ética anamnética», Eguzkilore $\mathrm{n}^{\circ} 22$. diciembre, 2008, pág.I93. 
facultar el continuar con la vida ${ }^{138}$. Para lo que, de forma solo aparentemente paradójica, el recuerdo de las víctimas, incluso a su modo por parte de la Administración de justicia a través del mismo proceso, es un punto de partida necesario ${ }^{\mathrm{I3}}$. $^{\mathrm{A}}$

\section{Conclusiones: el manantial de las víctimas}

Hemos tratado en este texto de presentar una posible guía de lectura desde la Victimología de «El manantial de la doncella» (Jungfrukällan, I960), una de las grandes obras del director sueco Ingmar Bergman. Por su profundidad, su carga emocional y su abordaje casi filosófico de diversos elementos y conceptos esenciales en este campo, creo que esta película constituye un excelente material docente de partida para la enseñanza universitaria de esa disciplina. Junto con estas sugerencias quedan todavía por explorar otras posibles lecturas (filosóficas, históricas, políticas, éticas y hasta religiosas) que también pueden aportar conocimiento en torno a la victimización y sus consecuencias. No hemos agotado las muchas posibilidades del filme sino centrado nuestro análisis en algunos elementos, presentes directamente en la película o sugeridos por ella, de especial relevancia en una primera aproximación a la disciplina victimológica.

La recuperación de la figura de la víctima y su posicionamiento cada vez más central son algunos de los rasgos más destacados de las últimas transformaciones de la justicia criminal y del Derecho penal. No obstante, la victimología, entendida como estudio científico de la víctima y de los procesos de victimización, cubriría un área de conocimiento más amplia. Se trata de un saber claramente interdisciplinar que, conectado estrechamente con la Criminología y centrado en el análisis de los diversos factores y consecuencias sociales, psicológicas jurídicas y económicas del delito desde el punto de vista de las víctimas, tiene también un carácter empírico y una aplicación práctica evidente. Hemos visto cómo desde los primeros desarrollos de la Victimología (muy enfocados hacia el análisis del grado de participación de las propias víctimas en la comisión de los delitos y, por tanto, acusados de culpabilizarlas) se ha pasado a una Victimología más activista centrada en la defensa de los derechos de las víctimas. Desde una Victimología del acto habríamos llegado a una Victimología de la acción.

Esto ha generado, en no pocos críticos, una postura recelosa hacia la Victimología a la que se le achaca haberse convertido más en un programa no académico de activismo social y defensa de los intereses de determinadas víctimas seleccionadas que en una

\footnotetext{
${ }^{138}$ Como señala Echeburúa, «por muy terrible que haya sido la experiencia vivida, siempre cabe la posibilidad de cerrar, total o parcialmente, la herida sufrida. No se trata de olvidar lo inolvidable (tarea, por lo demás, imposible), sino de no sentirse atrapado como en una jaula por los recuerdos del pasado. Lo que se pretende es recuperar la capacidad de hacer frente a las necesidades del presente y de mirar al futuro con esperanza» ECHEBURÚA, E., Superar un trauma: el tratamiento de las víctimas de sucesos violentos, cit., pág. 352.

${ }^{139}$ Aunque no es propiamente el caso planteado en el film, la memoria de las víctimas y su reparación supone un elemento esencial en el desarrollo de la denominada justicia de transición en escenarios de sociedades en transformación hacia la democracia desde contextos de violencia política y de violaciones masivas de derechos humanos. Además hay otro elemento de relación con la película puesto que muchas de las víctimas de estas situaciones en contextos de procesos de justicia transicional son víctimas familiares de personas asesinadas o desaparecidas en periodos de violencia. De hecho la fijación clara del concepto de víctima y la determinación del grupo de personas a las que se refiere es siempre uno de los aspectos más complejos e importantes del desarrollo de estos procesos. Para un completo recorrido sobre estas cuestiones puede consultarse por ejemplo: MARTín BERISTAIN, C., «Justicia y reconciliación. El papel de la verdad y la justicia en la reconstrucción de sociedades fracturadas por la violencia», Cuadernos de trabajo de Hegoa, n 27, 2000, págs. I42 .
} 
rigurosa disciplina científica. Estas críticas nos parecen algo injustas y provienen, en buena medida, de confundir Victimología con Victimismo. No obstante alertan de la necesidad de articular y desarrollar un tipo de Victimología que atienda, con rigor científico, a la necesidad de estudio de todo tipo de víctimas y procesos de victimización sin caer en las trampas de la jerarquización ni constituirse en la coartada científica para una serie de políticas criminales cada vez más punitivistas. Una nueva Victimología crítica, consciente de las paradojas y de las patologías sociales de la víctima, es posible. El apoyo a las víctimas y sus necesidades como uno de los rasgos definitorios de lo que debe ser una sociedad decente no necesariamente tiene por qué excluir, desde este abordaje, la racionalidad científica asociada a la Victimología como a cualquier otra disciplina académica.

En el análisis de los temas presentes o sugeridos directamente por el texto filmico bergmaniano, nos hemos detenido sobre todo en tres emociones: la compasión, el deseo de venganza y el sentimiento de pérdida. De hecho, en una sociedad y un contexto tan emocionalizado como el Derecho penal (sobre todo en lo referente a las víctimas de delitos graves como el de la película), las emociones juegan un papel determinante como catalizadores epistemológicos en el ámbito de la Victimología.

Hemos partido de la consideración del personaje de la doncella como víctima ideal y de cómo la compasión modela la percepción social de las víctimas dando en ocasiones lugar a procesos de jerarquización que generan el desplazamiento del foco de atención sobre determinadas formas de victimización dejando otras en penumbra (o directamente invisibilizándolas). También, a raíz de los usos políticos de la compasión, hemos analizado el proceso de desvictimización y un primer acercamiento a las transformaciones del papel de la víctima en la justicia criminal.

El deseo de venganza y la consumación de la misma por parte del personaje del caballero nos ha permitido seguir reflexionando, desde un punto de vista más histórico, sobre la transformación del papel de la víctima en el Derecho penal y la justicia criminal; desde la denominada por algunos como su edad de oro hasta el redescubrimiento de la misma a partir del auge de la Victimología pasando antes por el proceso de neutralización de la víctima que se deduce de la consolidación del carácter público del ius puniendi con la subsecuente expropiación del conflicto por parte del Estado como forma de evitar el ejercicio de la venganza privada. Esto nos ha llevado también a reflexionar sobre la pervivencia actual del carácter retributivo de la pena y sobre el auge del denominado populismo penal.

Finalmente, desde la reflexión sobre el sentimiento de pérdida de los familiares y personas cercadas, hemos tratado de plantear algunas cuestiones relacionadas con las víctimas secundarias o vicarias. Hemos abordado también las consecuencias del delito y el trauma de la pérdida para este tipo de víctimas en un sentido victimológico amplio y también el papel (y sus limitaciones) del Derecho entendido como gestor del dolor. Nos referimos también brevemente en esta última parte del análisis al concepto de memoria aplicado a las víctimas.

Volviendo por última vez a la película objeto de esta lectura victimológica, me gustaría concluir estas páginas con una propuesta personal de interpretación de la escena 
final del manantial ${ }^{\mathrm{T} 40}$. El manantial resulta un símbolo polisémico que muchos comentaristas han interpretado tradicionalmente en clave religiosa. Dejando al margen esa posible interpretación, quiero proponer una lectura que probablemente no estaba en las intenciones conscientes de Bergman pero que considero legítima y coherente con el análisis victimológico de su obra aquí abordado.

Desde ese punto de vista, el manantial sería una metáfora del dolor de las víctimas (directas e indirectas) que fluye sin cesar, a borbotones en un primer momento para después irse canalizando. Además el hecho de que sea un manantial cristalino, de aguas puras, remite a la percepción social de la inocencia de determinadas víctimas (lo que, como hemos visto, no está exento de paradojas y contradicciones). También el agua es fuente de vida y una metáfora del conocimiento. Es decir, en el fondo, nos gustaría contemplar ese mismo manantial como un trasunto simbólico de la propia Victimología como fuente de conocimiento que puede (y debe) ser utilizada con rigor científico para seguir construyendo una disciplina sólida y útil para las víctimas pero también para la sociedad en su conjunto. El manantial de la película de Bergman sería, en esta interpretación, el manantial de las víctimas.

\section{Bibliografía}

AcinAS, P., «Duelo en situaciones especiales: suicidio, desaparecidos, muerte traumática, Revista Digital de Medicina Psicosomática y Psicoterapia, nº I, vol. 2., 2012, pág. 2. (disponible en: http://www.psicociencias.com/revista/boletines/Duelo\%2oen\%2osituaciones\%2oespeciales. pdf; fecha de consulta: I0.09.20I4).

Aguilar Avilés, D., Estudios cubanos sobre victimología, I edición, Málaga, Grupo de Investigaciones EUMED, Universidad de Málaga, 20 oro.

Aguilera Rull, A., «La actualidad del análisis feminista del derecho al hilo de pronunciamientos judiciales recientes», Anales de la Cátedra Francisco Suárez, n 46, 2012, págs. I83-209.

AMIR, M., Patterns of Forcible Rape, Chicago, Chicago University Press, I97I.

ARRONA PALACIOS, A., «La influencia de la victimología en la justicia restaurativa y los programas de mediación», Quadernos de criminología, n 16, 2012, págs.6-II.

BARONA VILAR, S., «Influencias de la Unión Europea e instancias supranacionales en la tutela penal de la víctima, en la Justicia Restaurativa y la Mediación Penal», Revista Judicial, Costa Rica, $\mathrm{n}^{\circ}$ I08 Junio, 2013, págs. 47-69.

Baum, E., «Emociones, Justicia y Derechos Humanos», Revista Derecho y Ciencias Sociales. Octubre $\mathrm{n}^{\circ}$, $201 \mathrm{II}$, págs. 74-97.

BAZAN, I., «La pena de muerte en la Corona de Castilla en la Edad Media», Clio y Crimen, n 4, 2007 , págs. 306-352.

Bergman, I., Imágenes, Barcelona, Tusquets, I992, (trad. Uriz Torres, J).

Bernuz BeneiteZ, $\mathrm{M}^{2}$.J., «El sentido de las emociones en el Derecho penal», Nuevo Foro Penal, nº 8I, julio-diciembre, 2013, págs. 210-231.

Caravaca Llamas, C. «Política Social y asistencia a las víctimas de delitos en España: del reconocimiento legal a la protección social», Contribuciones a las Ciencias Sociales, marzo 20II, pág. 3 (disponible en: www.eumed.net/rev/cccss/II/).

Carrabine, E., Inganski, P., Lee, M., Plummer, K., South, N., Criminology: A Sociological Introduction, London, Routledge, 2004.

\footnotetext{
${ }^{140}$ Se trata de una de las más bellas escenas de toda la obra bergmaniana y una representación del milagro en el cine quizás solo comparable a la escena de la resurrección de «La palabra» (Ordet, I955) de Dreyer.
} 
Christie, N., «Conflicts as Property», British Journal of Criminology, vol. I7, nº I, I976, págs. I-I5.

— «The ideal victim», FATTAH, E.A. (ed.), From crime policy to victim policy, London, Macmillan, I986, págs. I7-30.

Cocteau, J., La voz humana. La gran separación, Barcelona, Nuevo Arte Thor, I986 (trad. BoACHACA, J.).

CóRdoba DE la LLAVE, R., «Consideraciones en torno al delito de agresión sexual en la Edad Media», Clio y Crimen, $\mathrm{n}^{\circ}$ 5, 2008, pág. I87-202.

CORREDOR, A.M., «Estudio cualitativo del duelo traumático de familiares de víctimas de homicidio según la presencia o ausencia de castigo», Revista Colombiana de Psicología, nº II, 2002, págs. $35-55$.

CRESSEY, D., «Research implications of conflicting conceptions of victimology», FATTAH, E.A. (ed.), Towards A Critical Victimology, New York, St. Martin's Press, I992, págs.57-73.

Del Rosal, B., «¿Hacia el Derecho penal de la postmodernidad?», Revista Electrónica de Ciencia Penal y Criminología, no. II, 2009 (disponible en http://criminet.ugr.es/recpc/II/recpcII-08.pdf).

ECHEBURÚA, E., «El valor psicológico del perdón en las víctimas y los ofensores», Eguzkilore, $\mathrm{n}^{\circ} 27$, 2013, págs. 65-72.

- Superar un trauma: el tratamiento de las víctimas de sucesos violentos, Madrid, Pirámide, 2004.

ECheburúA, E., De Corral, P., Amor, P.J., «Evaluación del daño psicológico en víctimas de delitos violentos», Psicothema, vol. I4, 2002, págs.139-146.

ELIAS, R., «Paradigms and Paradoxes of Victimology, International Victimology», SUMNER, C., ISRAel, M., O'Connell. M., SARre R., (eds.), International victimology: selected papers from the 8th international symposium, Canberra, Australian Institute of Criminology, I996, págs, 9-34.

FATTAH, E., «Da investigação ao ativismo,da academia ao partidarismo e o resultante empobrecimento da Vitimologia», SOFIA, N., FÁVERo, M., (coord.), Vitimologia: Ciência e ativismo, Coimbra, Almedina, 20ıo, pág. 49-86.

Foucault, M., Vigilar y castigar, Buenos Aires, S.XXI editores, 2002 (trad. GARZÓn Del CAmino, A.).

Frijda, N. H., (I994) «Lex Talionis: On Vengeance», VAn Goozen, S.M., VAn DE Poll, N. VAN DE Poll, N.E.,SERGEANT, J.A. (Ed.), Emotions: Essays on Emotion Theory, New Jersey, Lawrence Erlbaum Hillsdale, págs. 263-290.

Fuentes Osorio, J.L., «Los medios de comunicación y el Derecho Penal», Revista Electrónica de Ciencia Penal y Criminología, nº 7, 2005, págs. 3-4 (disponible en http://criminet.ugr.es/recpc).

GARCÍA-GIL, J. M., «Ingmar Bergman: el existencialismo en el cine o un verano con Ingmar», Isagogé, $\mathrm{n}^{\circ} 4,2007$.

GARLAND, D., La cultura del control. Crimen y orden social en la sociedad contemporánea, Barcelona, Gedisa, 2005 (trad. Sozzo, M.).

Gilligan, R., «Adversity, Resilience and Young People: The Protective Value of Positive School and Spare Time Experiences», Children and Society, n I4, 2000, págs. 37-47.

Giner AlegríA, A., «Aproximación psicológica de la victimología», Revista Derecho y Criminología, ${ }^{\circ}$ I, 20II, págs. 25-56.

GómEz GARCíA, J.A., «Derecho y cine: El rito, o el derecho y el juez según el realismo jurídico escandinavo», Revista de Derecho UNED, n. 3, 2008, pág. I05.

Hellen-Nicholas, A., «Silence and Fury: Rape and The Virgin Spring», Screening the past, $\mathrm{n}^{\circ} 29$, 20IO, pág. I- 8 (disponible en: http://tlweb.latrobe.edu.au/humanities/screeningthepast/28/rape-and-the-virgin-spring.html; fecha de consulta: I0.09.20I4).

Hentig, H. von, The Criminal and His Victim: Studies in the Sociology of Crime, New Haven,Yale University Press, I948.

Herrero Alonso, C., Garrido Martín, E., «Los efectos de la violencia sobre sus víctimas», Psicothema, vol. I4, 2002, págs.Iog-II7. 
Johnstone, G., «Penal Policy Making: Elitist, Populist or Participatory?», Punishment Q Society, $\mathrm{n}^{\circ} 2$, 2000, pág. I6I-180.

Karmen, A., Crime Victims. An introduction to Victimology, Belmont, Wadsworth, $20 \mathrm{IO}$.

KÜHNE, H.H., «Kriminologie: Victimologie der Notzucht», Juristische Schulung, nº 5, I986, págs. 388 394.

LANDROve DíAZ ,G., La moderna victimología, Ia edición, Valencia, Tirant lo Blanch, I998.

LARRAURI PIJOAN, E., «Victimología ¿Quiénes son las víctimas? ¿Cuáles sus derechos? ¿Cuáles sus necesidades?», Jueces para la democracia, $\mathrm{n}^{\circ}$ I5, I992, págs. 2I-3I.

— «Criminología crítica: Abolicionismo y Garantismo», Ius et praxis, vol. 4, n² 2, I998, págs. 27-64.

MADRID, A., La política y la justicia del sufrimiento, $\mathrm{I}^{\mathrm{a}}$ edición, Madrid, Trotta, $20 \mathrm{O}$.

MARTín BERISTAIN, C., «Justicia y reconciliación. El papel de la verdad y la justicia en la reconstrucción de sociedades fracturadas por la violencia», Cuadernos de trabajo de Hegoa, $\mathrm{n}^{\circ}$ 27, 2000 , págs. I-42.

MARTíneZ, M., «Populismo punitivo mayorías y víctimas», Nomos-Universidad de viña del Mar, $\mathrm{n}^{\circ}$ 2, 2008, págs. I83-199.

Mc Evoy, K., McConnachie, K., «Victimology in transitional justice: Victimhood, innocence and hierarchy», European Journal of Criminology, num 9 (2), 20I2, págs. 527-538.

Mendelsohn, B., «Une nouvelle branche de la science bio-psycho-sociale: la victimologie», Revue Droit Pénal et de Criminologie, 1958, págs.619-628.

Morillas Fernandez, D.L., Patro Hernandez, R.Mª, Aguilar Carceles, M.Mº, Victimología: un estudio sobre la víctima y los procesos de victimización, $\mathrm{I}^{\mathrm{a}}$ edición, Madrid, Dyckinson, $20 \mathrm{II}$.

NACiONES UnidAS, Declaración sobre los Principios Fundamentales de Justicia para las Víctimas de Delito y del Abuso de Poder, ARES/40/34 Resolución de la Asamblea General de Naciones Unidas, Anexo, 1985.

NeVes, S., FÁVERo, M., «A vitimologia e os seus percursos históricos, teóricos e epistemológicos», SofiA, N., FÁvero, M., (coord.) Vitimologia: Ciência e ativismo, Coimbra, Almedina, 20Io, págs. I3-48.

Nino, C. S., Ética y Derechos Humanos. Un ensayo de fundamentación, $2^{a}$ edición, Buenos Aires Astrea y Depalma, 2007 .

Nussbaum, M.C., Emociones políticas, Ia edición, Barcelona, Paidos, $20 \mathrm{I} 4$ (trad. SÁNCHEZ MosqueRA, A.).

Ochoa Cateleiro, A., «La indemnización de la víctima en el proceso penal español y la nueva directiva de la UE», Good Practics for protecting victims, 20I3, págs. I-I5 (disponible en http://www.protectingvictims.eu/upload/pages/65/Indemnizacion.it.en.pdf).

PAdial, J. J., «Venganza, realización de la libertad y guerra privada», Thémata. Revista de Filosofía, $\mathrm{n}^{\circ} 48$ julio-diciembre, 2013 , págs. 85-93.

Pérez Cuesta, M., Nicuesa, M.J., «Afrontar el proceso de duelo», Astudillo,W., García de Acilu,A., Mendinueta C., ArrietA, C., (eds.). Estrategias para la atención integral en la terminalidad, Bilbao, Sociedad Vasca de Cuidados Paliativos, I999.

PÉREZ Rivas, N., «Los derechos de las víctimas en la Unión Europea. Análisis de la Directiva 20I2/29/UE», Boletín CeDe UsC, febrero 20I4, págs. I-IO (disponible en http://revistas.usc.es/boletincede/documentos/EditorialFebrero2OI4_Derechosvictimas_Natal iaPerezRivas.pdf).

Pérez Trenado, M., «El proceso de duelo y la familia», Astudillo, W., Arrieta,C., Mendinueta, C., Vega de Seofne, I., (eds.), La familia en la terminalidad, Bilbao, Sociedad Vasca de Cuidados Paliativos, 1999.

Peters T., «Consideraciones teóricas sobre la victimología», Cuaderno Vasco de Criminología, n 2 , I988, págs. I07-I34.

ROIG TORRES, M., «Algunos apuntes sobre la evolución histórica de la tutela de la víctima de delito», Estudios penales $\gamma$ criminológicos, $\mathrm{n}^{\circ} 22,2000$, págs. 153-308. 
Romasanta Iglesias, O., CAlvo VARELA, C., «Jungfrukällan: um conto maravilhoso», Agália, n. 97$98 \mathrm{I}^{\circ}$ semestre.

RUtTER, M., «Psychosocial resilience and protective mechanisims», American Journal of Ortho psyquiatry, $\mathrm{n}^{\circ} 57$ (3), I987, págs. 316-331.

SANZ-Diéz DE Ulzurruz-Lluch, M., «La víctima ante el Derecho. La regulación jurídica de la víctima en el Derecho internacional, en el Derecho Europeo y en Derecho positivo español», Anuario de Derecho Penal y Ciencias Penales, vol. LVII 2004, págs. 219-310.

SCHAFFER, S., The victim and his criminal: a study in functional responsibility, $\mathrm{I}^{\mathrm{a}}$ Edición, New York, Random House, 1968.

SenNET, R., El respeto, Barcelona, Anagrama, 2 edición, 2003 (trad. Galmarini, M.A.)

SessAR, K., BeURSKens, A., BoERS, K., «Wiedergutmachung als Konfliktregelungsparadigma?», Kriminologisches Journal, vol.18, nº 2, I986, págs. 86-104

Simon, J. Governing through Crime: How the War on Crime Transformed American Democracy and Created a Culture of Fear, I Edición, Oxford, Oxford University Press, 2007, pág. I36.

SonTAG, S., Ante el dolor de los demás, Barcelona, Random House, 2003, pág.IIo.

Strubb, J., «Restorative Justice, Domestic Violence and Family Violence», Australian Domestic and Family Violence Clearinghouse, Issues, paper 9, 2004, págs. I-23.

TAMARIT Sumalla, J.M., «Paradojas y patologías en la construcción social, política y jurídica de la victimidad», InDret. Revista para el análisis del Derecho, $\mathrm{n}^{\circ}$ I, 20I3, págs.I-31.

Thury Cornejo, V., «¿El cine nos aporta algo para la enseñanza del Derecho?», Academia. Revista sobre enseñanza del Derecho, año 7, nº. I4, 2009, pág.60.

TÖRNQVIST, E., Strindberg in Bergman, 2013 (disponible en: http://ingmarbergman.se/en/universe/strindberg-bergman).

TORRAlba, F., PAlazZI, C., «El deber de recordar a las víctimas: ética anamnética», Eguzkilore $\mathrm{n}^{\circ} 22$. diciembre, 2008, págs.. I89-I95.

TRIgGs, J.A., Allegory and Naturalism in Ingmar Bergman's Medieval Films, I988 (disponible en http://triggs.djvu.org/global-language.com/triggs/Bergman/Bergman.html).

VAN DIJK, J.J., «Introducing victimology», VAN DiJK, J. J. M., VAN KAAM, R. G. H. WeMMERS, J. (eds.), Caring for crime victims: Selected proceedings of the Ninth International Symposium on Victimology, Amsterdam, August 25-29, I997, New York, Criminal Justice Press, págs. I-I2.

Vernon Young, V., «Jungfrukällan (The Well of the Virgin) by Ingmar Bergman», Film Quarterly, vol. I3, $\mathrm{n}^{\circ} 4$, I960, págs. 43-47.

Walklate, S., Victimology, Londres, Unwin Hyman, i989.

— «Can there be a progressive victimology?», International Review of Victimology, vol. 3, I994, págs.II5.

— «Reframing criminal victimization: Finding a place for vulnerability and resilience», Theoretical Criminology, I5(2), 20II, págs. I79-I94.

— «Sexual violence against women: Still a controversial issue for victimology?», International Review of Victimology, $\mathrm{n}^{\circ}$ 20, 2014, págs. 7I-84.

WeRTHAN, F., The show of violence, New York, Doubleday, I949.

Worden, J.W., El tratamiento del duelo: asesoramiento y terapia, Barcelona, Paidós, 2002. 


\section{Referencias legislativas}

LEY 35/I995 de II de Diciembre de ayudas y asistencia a las víctimas de delitos violentos y contra la libertad sexual que recoge esta posibilidad en determinadas circunstancias (BOE, nº. I26, 27 de mayo de 1997).

Ley OrgánicA io/I995, de 23 de noviembre, del Código Penal, BOE, nº 28I, 24 de noviembre de I995.

ReAl DeCReto Legislativo 8/2004, de 29 de octubre por el que se aprueba el Texto refundido de la Ley sobre Responsabilidad Civil y Seguro en la Circulación de Vehículos a Motor (BOE nº. 267 , de 5 de noviembre de 2004). 